\title{
DNA Repair Genes as Drug Candidates for Early Breast Cancer Onset in Latin America: A Systematic Review
}

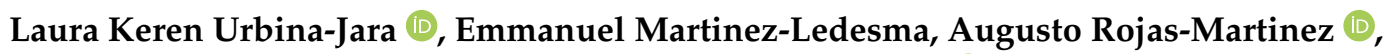 \\ Francisco Ricardo Rodriguez-Recio and Rocio Ortiz-Lopez * (1) \\ Tecnologico de Monterrey, Escuela de Medicina y Ciencias de la Salud, Monterrey 64710, Mexico; \\ A00823119@itesm.mx (L.K.U.-J.); juanemmanuel@tec.mx (E.M.-L.); augusto.rojasmtz@tec.mx (A.R.-M.); \\ franciscordzrecio97@gmail.com (F.R.R.-R.) \\ * Correspondence: rortizl@tec.mx; Tel.: +52-81-8888-2270
}

check for updates

Citation: Urbina-Jara, L.K.; Martinez-Ledesma, E.;

Rojas-Martinez, A.; Rodriguez-Recio, F.R.; Ortiz-Lopez, R. DNA Repair

Genes as Drug Candidates for Early Breast Cancer Onset in Latin America: A Systematic Review. Int. J. Mol. Sci. 2021, 22, 13030. https://doi.org/ $10.3390 /$ ijms222313030

Academic Editor:

Kazuhiko Kuwahara

Received: 8 October 2021

Accepted: 23 November 2021

Published: 2 December 2021

Publisher's Note: MDPI stays neutral with regard to jurisdictional claims in published maps and institutional affiliations.

Copyright: (c) 2021 by the authors. Licensee MDPI, Basel, Switzerland. This article is an open access article distributed under the terms and conditions of the Creative Commons Attribution (CC BY) license (https:// creativecommons.org/licenses/by/ $4.0 /)$.

\begin{abstract}
The prevalence of breast cancer in young women (YWBC) has increased alarmingly. Significant efforts are being made to elucidate the biological mechanisms concerning the development, prognosis, and pathological response in early-onset breast cancer (BC) patients. Dysfunctional DNA repair proteins are implied in BC predisposition, progression, and therapy response, underscoring the need for further analyses on DNA repair genes. Public databases of large patient datasets such as METABRIC, TCGA, COSMIC, and cancer cell lines allow the identification of variants in DNA repair genes and possible precision drug candidates. This study aimed at identifying variants and drug candidates that may benefit Latin American (LA) YWBC. We analyzed pathogenic variants in 90 genes involved in DNA repair in public BC datasets from METABRIC, TCGA, COSMIC, CCLE, and COSMIC Cell Lines Project. Results showed that reported DNA repair germline variants in the LA dataset are underrepresented in large databases, in contrast to other populations. Additionally, only six gene repair variants in women under 50 years old from the study population were reported in BC cell lines. Therefore, there is a need for new approaches to study DNA repair variants reported in young women from LA.
\end{abstract}

Keywords: DNA repair genes; breast cancer in young women; breast cancer datasets; cell lines; therapy

\section{Introduction}

Breast cancer (BC) is one of the main causes of death in women around the world [1], despite vast efforts to improve this outcome. Globally, an increase in BC is observed in women with ages between 35 and 54 years [2,3]. For example, in the United States, more than 12,000 women under 40 years old (y.o.) are diagnosed with BC each year [4]. Besides the rising $\mathrm{BC}$ incidence in young women $<40$ y.o. (YWBC) [5], more aggressive cancers have been observed in younger women [6]. At diagnosis, YWBC patients frequently present poorly differentiated and aggressive tumors characterized by lymph node invasion, deficiency of hormonal receptors, overexpression of human epidermal growth factor receptor type 2 (HER2), high proliferation rates, and advanced stage at diagnosis [7-10]. Likewise, higher occurrences of triple-negative breast cancer (TNBC) and basal-like types are observed in YWBC, both associated with worse prognosis [10]. Therefore, it is required to elucidate the underlying biological mechanisms implicated in YWBC development.

Studies have shown multiple altered variants in DNA repair genes implied in BC predisposition, development, and outcome [11-14], including BRCA and non-BRCA genes. Among these, pathogenic variants in the high penetrance $B R C A 1 / 2$ genes account for $50-60 \%$ and the remaining variants, to non-BRCA genes of moderate and low penetrance, including ATM, PALB2, RAD51, and BARD1, all involved in double-strand break repair pathways [15-21]. For this reason, it is relevant to elucidate the mechanisms of DNA repair genes in BC, using different approaches such as in silico, in vitro, and in vivo models. 
A large amount of basic knowledge on $\mathrm{BC}$ is derived from in vivo and in vitro studies using BC cell lines, which provide a source of homogeneous materials that self-replicate. Therefore, cell lines are model systems useful to study cancer biology [22]. Moreover, the use of cancer cell lines is key to identify new drug targets and for the improvement of current therapeutic options focusing on drug sensitivity and resistance [23-28]. Hence, it is essential to obtain information about the genomic context of each cell line model to draw reliable conclusions on drug sensitivity in cell lines resembling the molecular characteristics of YWBC [29].

The need for reproducibility in clinical research brought a plethora of publicly available databases. Databases for cancer studies provide a trustworthy and useful resource to perform different analyses due to their large compilation of BC cases, including clinical and genomic data [30]. A benefit of database analysis is the discovery of elements obtained from the collection of samples of a specific condition to guide functional in vitro studies. In this way, we can test causal hypotheses and search for new therapeutic agents.

Although there are abundant clinical studies on $B C$, there is low representativeness of minorities in clinical databases [31]. While there are several reports of germline and somatic variants in BC from Latin America (LA), they are scarce compared to other populations. For this reason, this study aimed at providing preliminary information to address the lack of data regarding YWBC in our region. For this, we focus on contrasting DNA repair variants for BC reported in The Cancer Genome Atlas (TCGA) and the Molecular Taxonomy of Breast Cancer International Consortium (METABRIC) with DNA repair variants reported for $\mathrm{BC}$ in our subcontinent [32]. In addition, we searched for these LA variants in public repositories of drug response cancer cell lines to evaluate drug susceptibility.

\section{Results}

\subsection{Tumor Samples Data for $Y W B C$}

Table 1 describes the clinical information from METABRIC and TCGA databases and shows distinctions regarding YWBC. In METABRIC, the youngest reported patient was a 21.9 y.o. woman with mixed ductal and lobular BC, HER2+, and known somatic variants in TP53, NCOA3, MUC16, and AHNAK genes (sample ID, MB-3467). In addition, the METABRIC sample MTS-T1284 (47 y.o., ER+, ductal BC) presented variants in APC, ATR, $B R C A 1$, and FANCA genes. On the other hand, from the 292 samples aged $<50$ years in TCGA, only $11(3.8 \%)$ samples were described as Hispanic-Latino. The mean age at diagnosis for this group was 42.4 years, the mean overall survival (OS) was 45 months, while the shortest and longest reported OS was 14.6 and 96 months, respectively.

Table 1. Clinical characteristics of patients $<50$ y.o. from METABRIC and TCGA datasets.

\begin{tabular}{ccc}
\hline Clinical Characteristics & METABRIC & TCGA \\
\hline Total samples clinical data & 567 & 292 \\
Mean age at diagnosis (years) & 42.4 & 42.4 \\
Youngest age at diagnosis (years) & 21.9 & 26.0 \\
Mean OS (months) & 134.1 & 40.4 \\
Lowest OS (months) & 1.4 & 0.0 \\
Highest OS (months) & 337 & 283 \\
BC Subtype & & \\
Lum A & $22.2 \%$ & $44.9 \%$ \\
Basal & $14.6 \%$ & $20.2 \%$ \\
Claudine-low & $10.6 \%$ & 0 \\
HER2 & $9.3 \%$ & $5.5 \%$ \\
Lum B & $8.8 \%$ & $16.8 \%$ \\
Normal & $9.2 \%$ & $4.1 \%$ \\
NA & $25.3 \%$ & $8.5 \%$ \\
Total samples & 567 & 292 \\
\hline
\end{tabular}


Information concerning DNA repair variants characteristics from METABRIC and TCGA samples $<50$ y.o. are presented in Table 2. Interestedly, the Hispanic-Latino sample TCGA-EW-A2FV-01 presented variants in 23 DNA repair genes (APEX1, ATM, CCNB2, CHEK1, CHEK2, FANCA, FANCD2, MSH3, PARP9, PMS2, POLD1, POLE, RAD50, RECQL4, RECQL5, REV3L, RIF1, RPA2, RPA4, SMC2, SMC3, TOP2A, and WRN).

Table 2. Features of the METABRIC and TCGA DNA repair variants.

\begin{tabular}{ccc}
\hline & METABRIC & TCGA \\
\hline Total samples (all ages) & 2509 samples & 1084 samples \\
Total variants all samples, all genes & 17,272 variants & 130,495 variants \\
Patients $<50$ years old & & \\
Total samples & 567 samples & 292 samples \\
Total variants all genes & 3839 variants & 1693 variants \\
Top 5 mutated genes & TP53, PIK3CA, MUC16, & TP53, PRKDC, $A T M$, \\
Reported DNA repair variants & SYNEI1, and $A H N A K 2$ & BRCA2 and $B R C A 1$ \\
Reported DNA repair genes & 420 variants & 269 variants \\
Samples with DNA repair variants & 11 genes & 90 genes \\
Top reported DNA repair genes & TP53, ATR, and FANCA & TP53, ATM, and POLQ \\
Gene with most variants & TP53 (275 variants) & TP53 (80 variants) \\
Most frequent variant & TP53 p.R175H & TP53 p.R175H \\
& $(12$ samples) & (6 samples) \\
Sample with most reported DNA & MTS-T1284, 4 variants in & TCGA-EW-A2FV-01, 23 \\
repair variants & $A P C, A T R, B R C A 1$, and & variants in 23 genes \\
\hline
\end{tabular}

Figure 1 shows the percentages of tumor subtypes observed in METABRIC and TCGA for BC samples $<50$ y.o. METABRIC dataset subtype classification includes Claudinelow subtype in contrast to TCGA. In METABRIC, the only patient in the age group 20-25 years had a HER2 subtype. The most common subtypes by age group were the following: basal and luminal A subtypes in the $25-30$ years (50 and 25\%, respectively), claudin-low and basal subtypes in the 30-35 years (33.3 and 20\%, respectively), basal subtype in the $35-40$ years ( $30 \%$ ), and luminal A subtype in the $40-45$ and the $45-50$ years (27.9 and $40.5 \%$, respectively) (Figure 1a). We performed a Chi-squared test to assess differences among the six age groups, mainly between the groups of $20-35$ y.o versus $35-50$ y.o. groups, observing basal and luminal A breast cancer subtypes as predominant. Interestingly but worrisome, the basal subtype was more frequent for age groups below 40 years.

In TCGA (Figure 1b), the luminal A subtype was the highest reported for all age groups (from $35 \%$ in the $30-35$ years group up to $66.7 \%$ in the $25-30$ years group). Luminal B subtype was present in the $30-35$ years group (25\%) and $40-45$ years group $(21.7 \%)$. Again, the basal subtype was prevalent in young age groups: the 25-30 years group (16.7\%), 35-40 years group (25.4\%), $40-45$ years group (20.5\%), and $45-50$ years group $(21.31 \%)$.

We analyzed the overall survival in the METABRIC and TCGA data for women $<50$ years for the 6 and 5 different age groups, respectively (Figure 2). For METABRIC, the lowest median overall survivals were 38.8 and 51.40 months in the groups 20-25 and 25-30 years, respectively. The 45-50 years group presented the longest median survival and had the highest number of patients. (Figure 2a). For the TCGA dataset, the 30-35 years groups had the worst overall survival, while the $40-45$ years had the best (Figure 2b) $[33,34]$. This highlights the importance of a timely diagnosis of $\mathrm{BC}$ for young patients. Figure S1 presents survival analyses with BC subtype for both METABRIC and TCGA. 


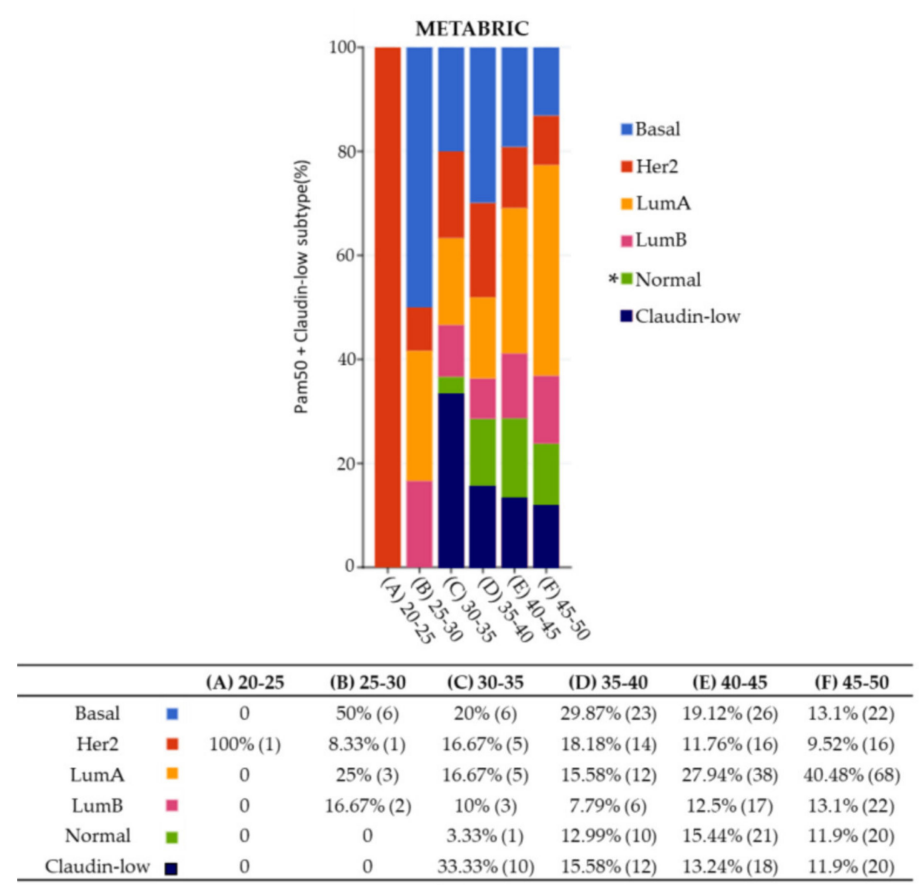

(a)

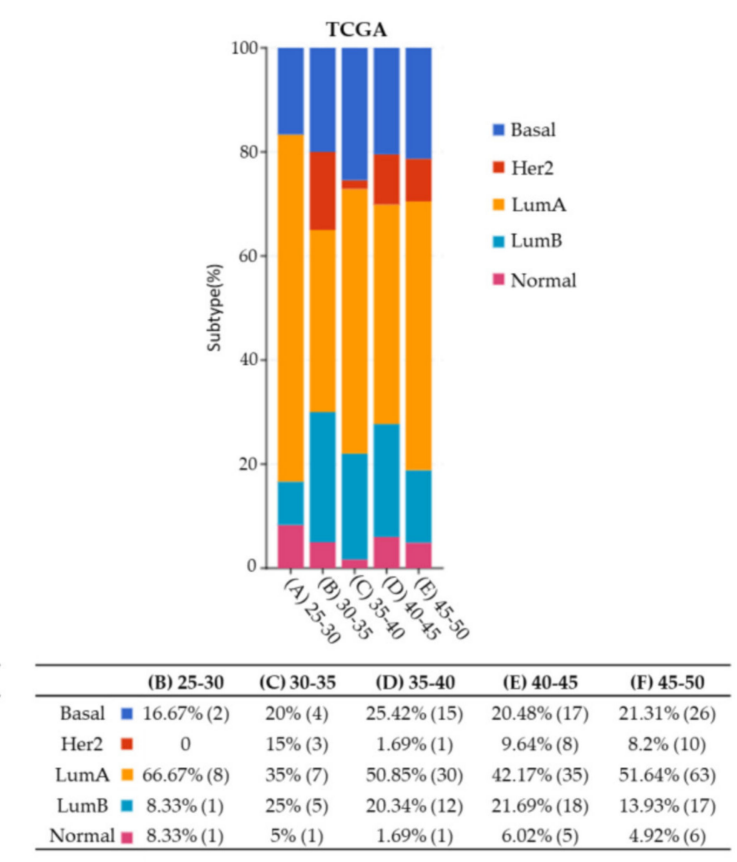

(b)

Figure 1. METABRIC and TCGA under 50 y.o. BC subtype. (a) METABRIC dataset divided into six different age groups. Chi-squared test $p$-value 5.705e-4. (b) TCGA dataset consisted of five age groups. Chi-squared test $p$-value 0.616 . The number of samples is indicated in parentheses. * Normal-like is similar to luminal A, PR and/or ER positive, HER2 negative, and low Ki-67 levels.

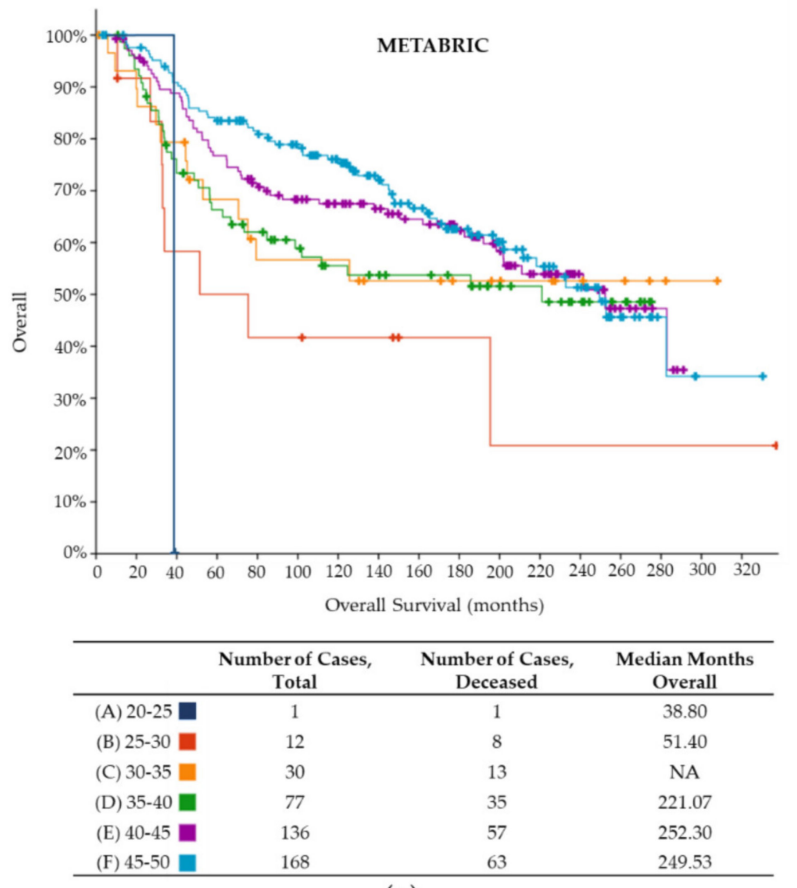

(a)

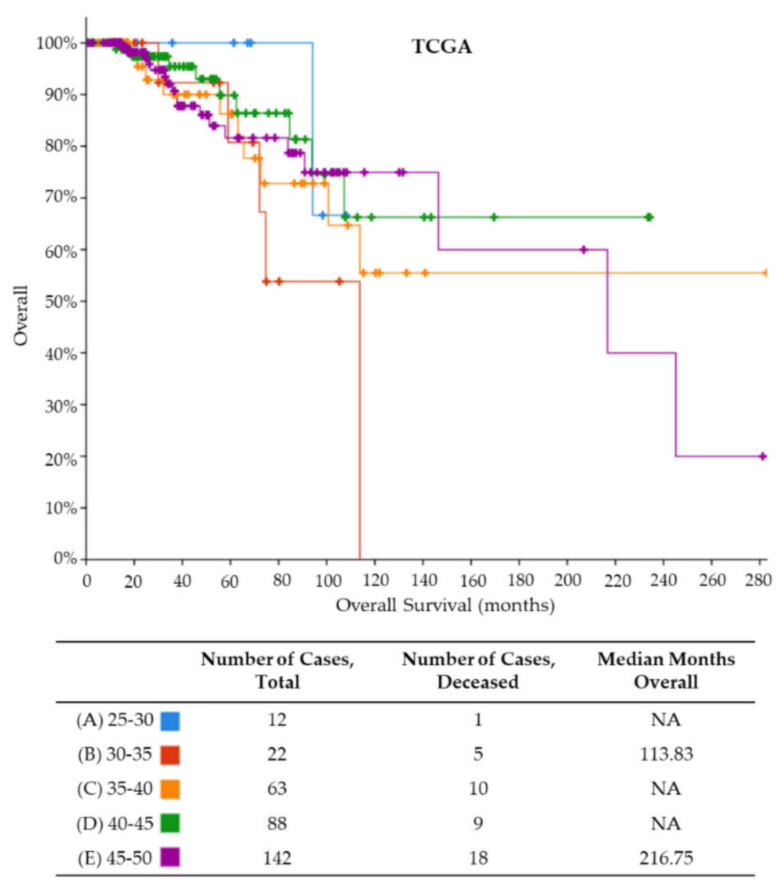

(b)

Figure 2. Overall survival METABRIC and TCGA under 50 y.o. The overall survival for six different age groups of women is represented in months. (a) METABRIC. The group of 30-35 y.o. in orange displays better overall survival (over 55\% for 300 months), while the only case in the 20-25 years group shows the worst survival. The $45-50$ years group concentrates more BC cases. Log-rank test $p$-value 0.0252. (b) TCGA. The 30-35 years group shows the worst overall survival, contrary to the METABRIC dataset. The best overall survival is observed for the $40-45$ years group (over $60 \%$ survival at 220 months). Log-rank test $p$-value 0.454 . NA, not available. 
Furthermore, we searched for pathogenic variants in the METABRIC and TCGA datasets for the same established age groups. In Figure 3, the 10 most frequent altered genes in YWBC are presented by age groups for both METABRIC and TCGA data. In METABRIC, pathogenic variants in the TP53 gene were observed in all groups, followed by variants of the PIK3CA gene. The sample of the only patient in the 20-25 years group had pathogenic variants in NCOA3, TP53, AHNAK, and MUC16 (Figure 3a). The TCGA dataset, in general, presented different results for the most frequently mutated genes in women $<50$ y.o. like the frequency of CAMK1G, CELF2, and NDFIP2 in women aged 35-50 y.o., in contrast to METABRIC data. Some similarities to METABRIC data include TP53 and PIK3CA genes as the most altered in the five age groups. GATA3 was present in all groups (Figure $3 b$ ) $[33,34]$.

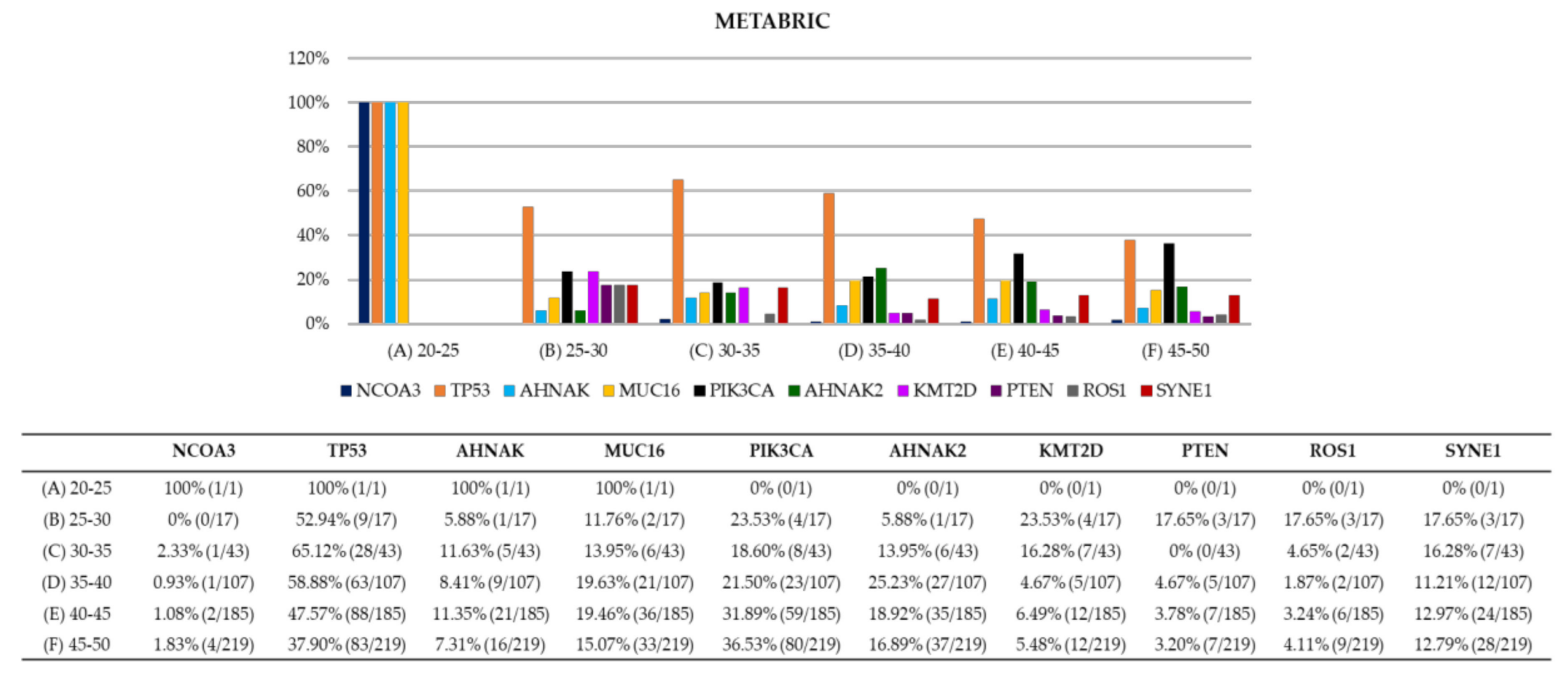

(a)

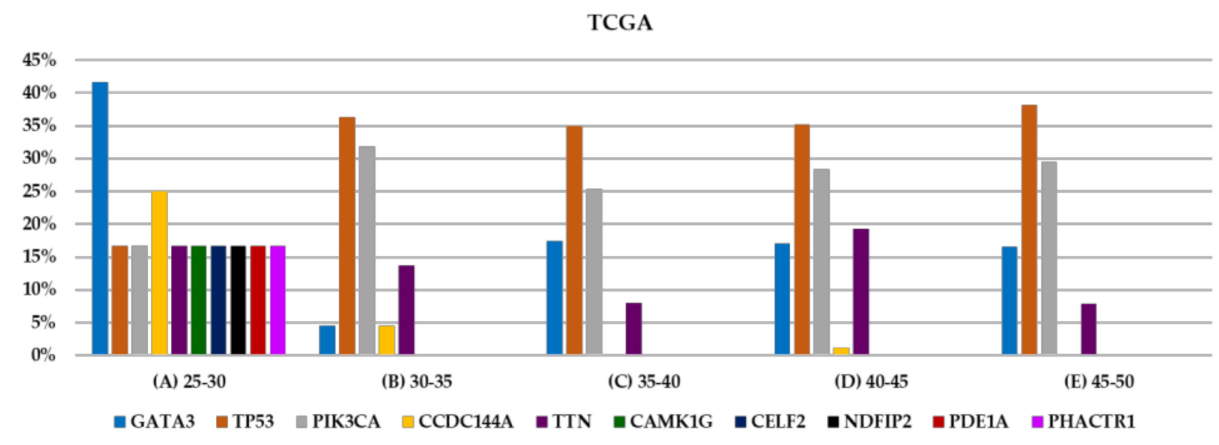

\begin{tabular}{ccccccccccc}
\hline & GATA3 & TP53 & PIK3CA & CCDC144A & TTN & CAMK1G & CELF2 & NDFIP2 & PDE1A & PHACTR1 \\
\hline (A) $25-30$ & $41.67 \%(5 / 12)$ & $16.67 \%(2 / 12)$ & $16.67 \%(2 / 12)$ & $25.0 \%(3 / 12)$ & $16.67 \%(2 / 12)$ & $16.67 \%(2 / 12)$ & $16.67 \%(2 / 12)$ & $16.67 \%(2 / 12)$ & $16.67 \%(2 / 12)$ & $16.67 \%(2 / 12)$ \\
(B) $30-35$ & $4.55 \%(1 / 22)$ & $36.36 \%(8 / 22)$ & $31.82 \%(7 / 22)$ & $4.55 \%(1 / 22)$ & $13.64 \%(3 / 22)$ & $0 \%(0 / 22)$ & $0 \%(0 / 22)$ & $0 \%(0 / 22)$ & $0 \%(0 / 22)$ & $0 \%(0 / 22)$ \\
(C) $35-40$ & $17.46 \%(11 / 63)$ & $34.92 \%(22 / 63)$ & $25.40 \%(16 / 63)$ & $0 \%(0 / 63)$ & $7.94 \%(5 / 63)$ & $0 \%(0 / 63)$ & $0 \%(0 / 63)$ & $0 \%(0 / 63)$ & $0 \%(0 / 63)$ & $0 \%(0 / 63)$ \\
(D) $40-45$ & $17.05 \%(15 / 88)$ & $35.23 \%(31 / 88)$ & $28.41 \%(25 / 88)$ & $1.14 \%(1 / 88)$ & $19.32 \%(17 / 88)$ & $0 \%(0 / 89)$ & $0 \%(0 / 89)$ & $0 \%(0 / 89)$ & $0 \%(0 / 89)$ & $0 \%(0 / 89)$ \\
(E) $45-50$ & $16.55 \%(23 / 139)$ & $38.13 \%(53 / 139)$ & $29.50 \%(41 / 139)$ & $0 \%(0 / 142)$ & $7.91 \%(11 / 139)$ & $0 \%(0 / 142)$ & $0 \%(0 / 142)$ & $0 \%(0 / 142)$ & $0 \%(0 / 142)$ & $0 \%(0 / 142)$ \\
\hline
\end{tabular}

(b)

Figure 3. METABRIC and TCGA under 50 y.o. 10 most frequently mutated genes. (a) The METABRIC dataset is divided into six different age groups. Pathogenic variants in TP53, PIK3CA, and MUC16 are frequently observed in all group ages. Frequencies of pathogenic variants for each gene group are illustrated. (b) The TCGA dataset consisted of five age groups. Pathogenic variants in TP53, PIK3CA, and GATA3 are moderately prevalent in women $<50$ y.o. Five genes such as CAMK1G, CELF2, NDFIP2, PDE1A, and PHACTR1 were observed in two patients only (16.67\%) from the 25-30 age group.

Moreover, we collected mutation load in these databases according to different age groups (Figure 4). We specify that the numbers mentioned in this paragraph are expressed 
in $\log 2$ as displayed in Figure 4. For METABRIC, the median mutation count was 2.58 and maximum 4.45 for the 25-30 y.o. group. In the following group of 30-35-year-olds, the maximum mutation count was 4.9 and a reported median of 2.32 . The maximum count for the group of 35-40 y.o. was 3.9 and the median of 2.32. Likewise, a high mutation count of 4.64 was observed in the 40-45 y.o. group with a median of 2.12. Lastly, for the $45-50$ y.o. group median mutation count was 2.32, and the maximum reported of 4.64 (Figure $4 \mathrm{a}$ ). For the TCGA dataset, five age groups were analyzed. In the 25-30 y.o. a median 5.18 mutation count was reported with a maximum of 8.0. A median of 5.28 was observed in the 30-35 age group with a maximum of 7.35. For the 35-40 y.o group a maximum mutation count of 8.14 was reported with a median of 5.02. Moreover, a maximum of 8.48 and a median of 5.38 were observed in the $40-45$ age group. Lastly, in the 45-50 y.o. group a maximum mutation count of 7.6 and a median of 5.09 was reported (Figure 4b). Curiously, the sample TCGA-EW-A2FV from a 39 y.o. woman has a mutation count of 12. Thus, a higher mutation load was observed in TCGA than METABRIC samples. This could be due to differences in screened populations, TCGA included women from more diverse ethnicities in contrast with the METABRIC study [35].

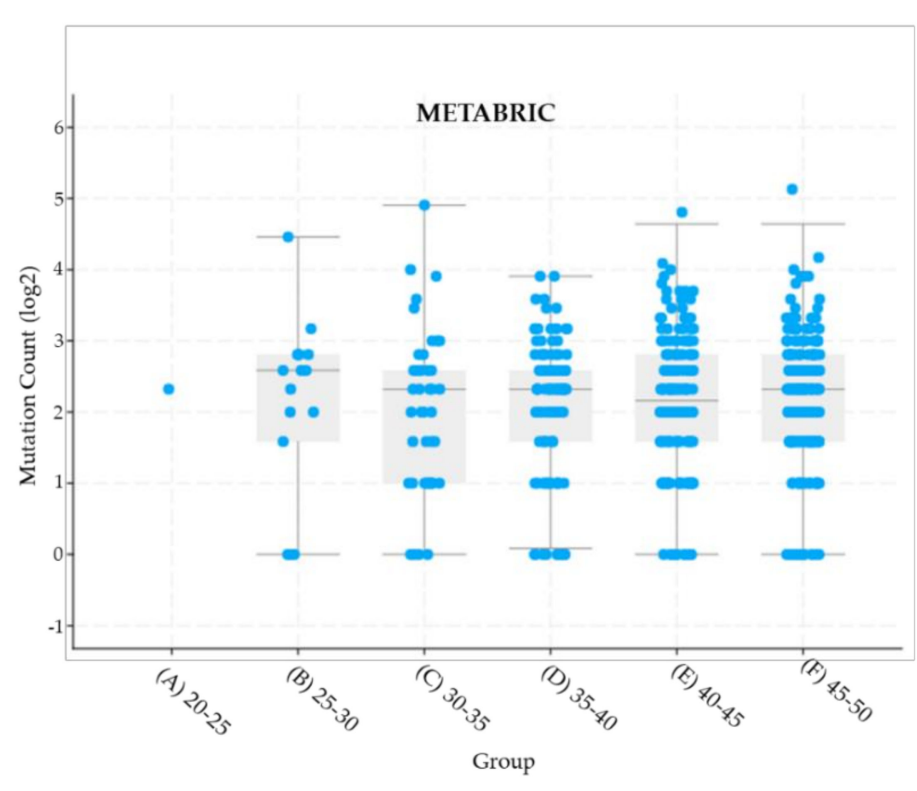

(a)

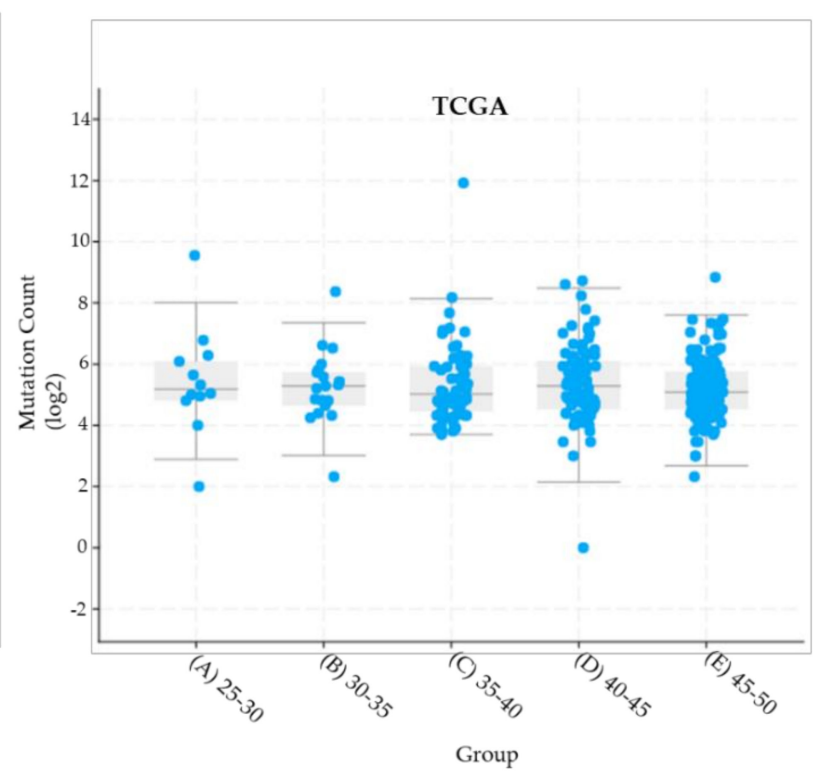

(b)

Figure 4. METABRIC and TCGA mutation load in patients with breast cancer under 50 y.o. (a) METABRIC dataset divided in six different age groups. Derived from Kruskal-Wallis test, $p$-value 0.910. (b) TCGA dataset consisted of five age groups. Derived from Kruskal-Wallis test, $p$-value 0.830. In general, a higher mutation count was observed in TCGA than METABRIC samples.

\subsection{BC Cell Line Variants and DNA Repair Genes}

For the analysis of cell line variants harboring mutated DNA repair genes two public databases were reviewed, CCLE and COSMIC Cell Lines Project. A total of 2477 cancer cell lines were retrieved, 1457 from CCLE and 1020 from COSMIC Cell Lines Project. Data was filtered for BC and DNA repair genes resulting in $67 \mathrm{BC}$ cell lines for further analysis. Information regarding the analyzed BC cell lines is shown in Table S3. Cell lines were compared with our database of LA variants in DNA repair genes [32]. The final selection of cell lines consisted of seven BC cell lines: AU565, HCC1143, HCC1395, HCC1937, HCC70, MDA-MB468, and SKBR3, all carrying variants in BRCA1 and TP53 genes, as shown in Figure 5. Information on onset age, country, and variant was available for all the entries. Contributing countries for this dataset are limited to Brazil, Argentina, and Uruguay. Variants in BRCA1 and TP53 observed in BC cell lines are represented in the LA dataset (Figure 6) [33,34]. Two variants are displayed for BRCA1, c.5251C > T 
(R1751*) a nonsense variant, and c.5266dupC (Q1756Pfs) a frameshift variant. TP53 presents three different variants, the missense variant c.743G > A (R248Q), the missense variant c.818G > A $(\mathrm{R} 273 \mathrm{H})$, and the nonsense variant c.916C $>\mathrm{T}\left(\mathrm{R} 306^{*}\right)$. Comparing the 717 variants for 15 DNA repair genes that were reported in women under 50 y.o. with BC in Latin America, it can be inferred that the presence of these variants in BC lines is low. Therefore, only six variants for two genes (BRCA1 and TP53) were observed in seven cell lines of a total of $121 \mathrm{BC}$ cell lines analyzed. This analysis reflects the low representation of gene variants in BC lines besides BRCA1/2 and TP53 in LA women $<50$ y.o. Information concerning the biological effects and clinical implications of each variant is described in Table S1.

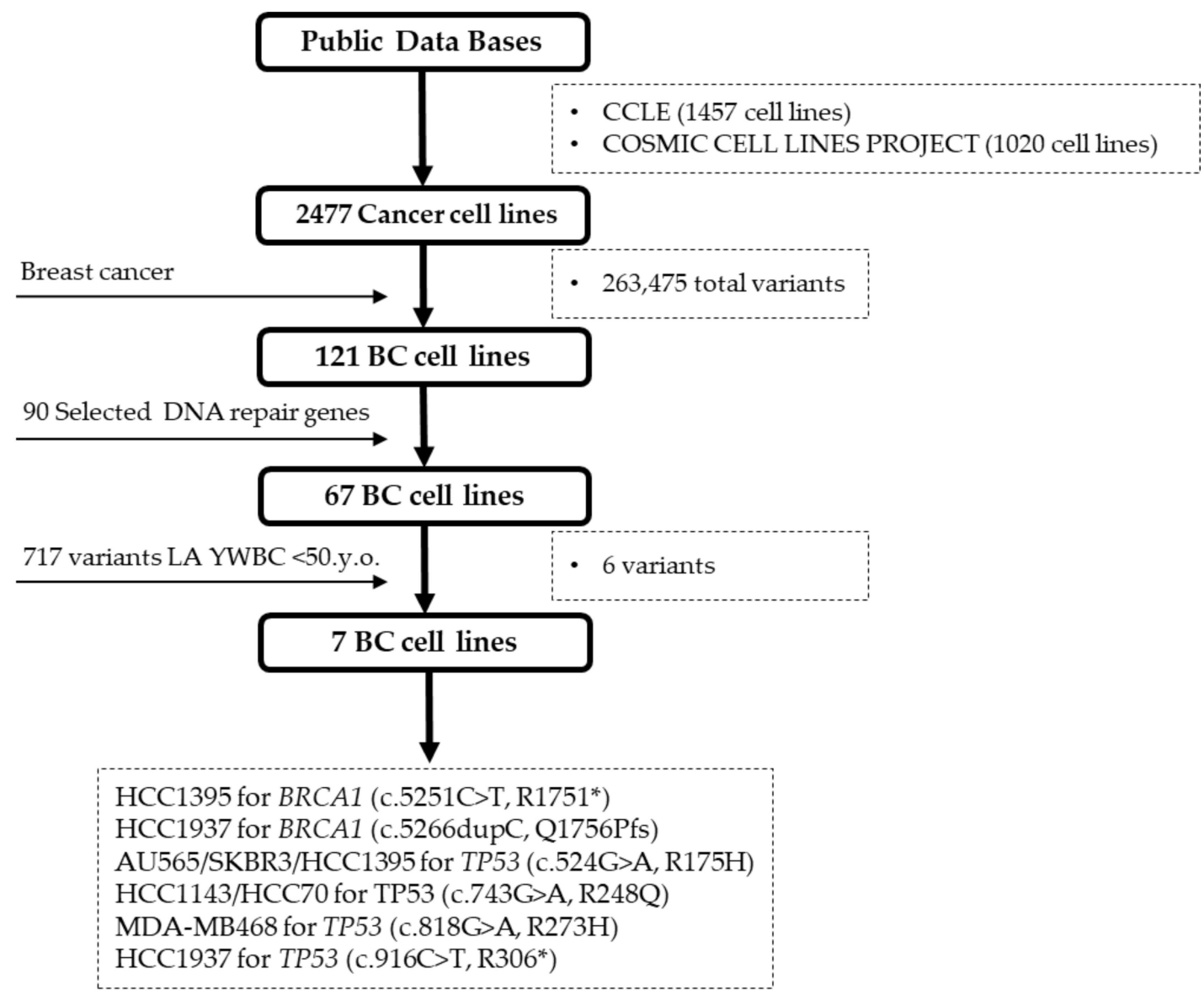

Figure 5. BC cell lines variants and DNA repair genes. CCLE and COSMIC Cell Lines Project databases were analyzed and a total of 2477 cancer cell lines were retrieved. Sixty-seven cell lines corresponded to BC. Cell lines were filtered for 90 DNA repair variants and 717 LA reported variants resulting in the selection of seven BC cell lines: AU565 (c.524G>A, TP53), HCC1143 (c.743G>A, TP53), HCC1395 (c.5251C>T, BRCA1; c.524G>A, TP53), HCC1937 (c.916C>T, TP53; c.5266dupC, BRCA1), HCC70 (c.743G>A, TP53), MDA-MB648 (c.818G>A, TP53), and SKBR3 (c.524G>A, TP53). * Truncating variant.

\subsection{Drug Sensitivity and Cell Lines with Altered Repair Mechanisms}

For this analysis, the GDSC2 dataset from the Genomics of Drug Sensitivity in Cancer repository was evaluated. A total of 30 cancer types, 192 drugs, and 135,242 entries were retrieved. No PARP inhibitors were tested in these drug databases for the selected cell lines. Later, different filters were applied to obtain specific information. First, the BC filter displayed seven different BC cell lines. For this analysis, the concentration range selected was $\leq 1 \mu \mathrm{M}$ for all drugs. Followed by a selection of drugs that displayed an area under the curve (AUC) lower than 0.6. With this information, LA variants from young women previously selected in this study were compared and drugs with the best performance in cell line assays were retrieved. Six BC cell lines were retrieved: AU565, HCC1143, HCC1395, 
HCC1937, HCC70, and MDA-MB-468. A total of 27 candidate drugs were collected from this analysis, including drugs impacting different pathways such as apoptosis regulation, cell cycle, DNA replication, IGF1R signaling, mitosis, protein stability and degradation, and receptor tyrosine kinase (RTK) signaling (Figure 7).

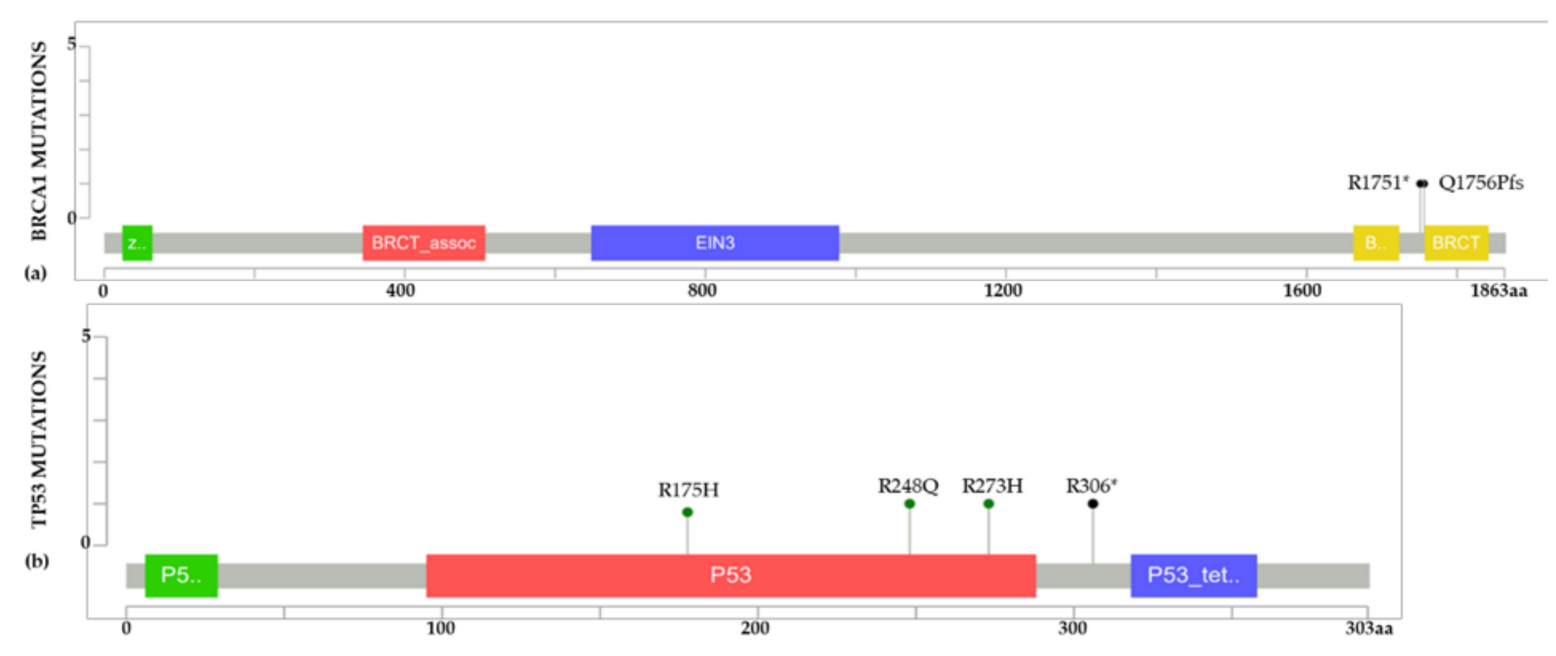

Figure 6. BRCA1 and TP53 LA variants in BC cell lines. (a) BRCA1 nonsense variant R1751* (c.5251C > T) and frameshift variant Q1756Pfs (c.5266dupC) are displayed. (b) TP53 missense variant R248Q (c.743G > A), missense variant R175H (c.524G > A), missense variant R273H (c.818G > A), and nonsense variant R306* (c.916C > T) are represented. * Truncating variant.

Further, Figure 8 shows the fitted IC50 $\mu \mathrm{M}$ concentration of each of the 27 candidate drugs from this search. Drugs such as dactinomycin, docetaxel, and vinorelbine have the lowest $\mu \mathrm{M}$ concentration. On the other hand, drugs like ULK1_4989 and acetalax are the ones displaying the highest $\mu \mathrm{M}$ concentration. Table S4 presents all drug information for these analyses.

Herein Table 3 describes the 27 candidate drugs with their putative target and the pathway in which each drug interacts. In addition, BC cell lines reporting these drugs are displayed. 


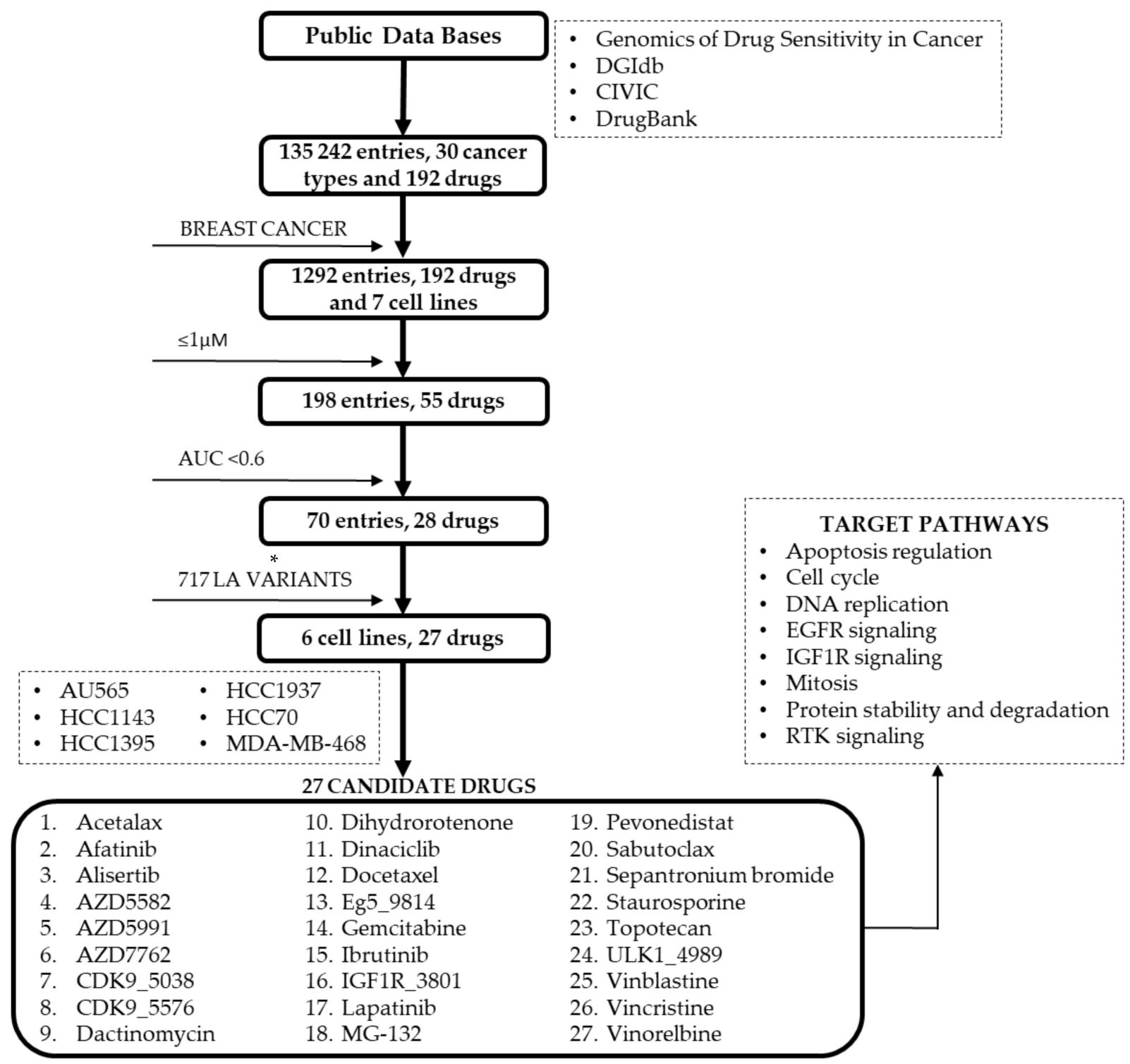

Figure 7. BC cell lines and variants in DNA repair genes. Four different databases were searched for this analysis obtaining information regarding 30 cancer types and 192 drugs. The BC filter data reduced 1292 entries to seven BC cell lines. Considering a concentration $\leq 1 \mu \mathrm{M}$ for all drugs and an AUC $<0.6$ the search was narrowed to 70 entries and 28 drugs. Only six BC cell lines were selected after filtering cell lines carrying LA variants (AU565, HCC1143, HCC1395, HCC1937, HCC70, and MDA-MB-468) and 27 candidate drugs. Pathways impacted by these drugs include apoptosis regulation, cell cycle, DNA replication, EGFR signaling, IGF1R signaling, mitosis, protein stability and degradation, and RTK signaling. * Variants selected from our previous study [32]. 


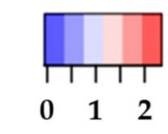

$\mu$ Molar (-log10)

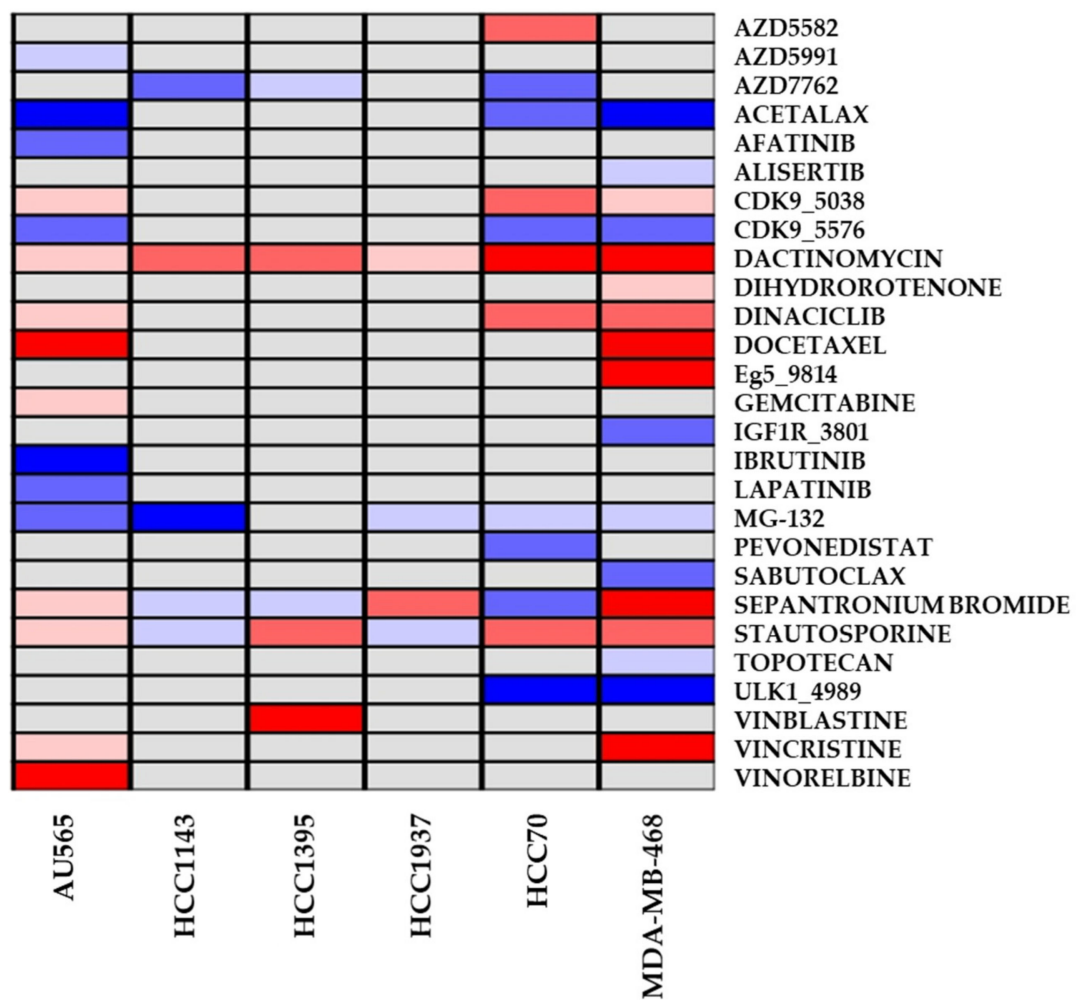

Figure 8. The 27 candidate drug $\mu \mathrm{M}$ concentration for fitted IC50, considering the parameters previously described in Figure 7, concentration $\leq 1 \mu \mathrm{M}$ and AUC $<0.6$. Each of the 27 candidate drugs with best results according to previously mentioned criteria are shown in this image. Drugs displaying the lowest concentrations include dactinomycin, docetaxel, and vincristine. On the other hand, drugs with highest concentrations are acetalax, ibrutinib, and ULK1_4989. Drug concentrations $(\mu \mathrm{M})$ are displayed in blue and red shades. Grey spots represent data not available.

Table 3. Drugs identified for treated BC cell lines with LA variants.

\begin{tabular}{cccc}
\hline Drug Name & Cell Lines & Putative Target & Pathway Name \\
\hline Acetalax & A565, HCC70, MDA-MB-468 & - & Unclassified \\
Afatinib & A565 & ERBB2, EGFR & EGFR signaling \\
Alisertib & MDA-MB-468 & AURKA & Mitosis \\
AZD5582 & HCC70 & XIAP, cIAP & Apoptosis regulation \\
AZD5991 & A565 & MCL1 & Apoptosis regulation \\
AZD7762 & HCC1143, HCC1395, HCC70, & CHEK1, CHEK2 & Cell cycle \\
CDK9_5038 & A565, HCC70, MDA-MB-468 & CDK9 & Cell cycle \\
CDK9_5576 & A565, HCC70,MDA-MB-468 & CDK9 & Cell cycle \\
& A565, HCC1143, HCC1395, & & Other \\
Dactinomycin & HCC1937, HCC70, & RNA polymerase & \\
Dihydrorotenone & MDA-MB-468 & & Unclassified \\
Dinaciclib & MDA-MB-468 & Cell cycle \\
Docetaxel & A565, HCC70, MDA-MB-468 & CDK1, CDK2, CDK5, CDK9 & Mitosis \\
Eg5_9814 & A565, MDA-MB-468 & Microtubule stabilizer & Other \\
Gemcitabine & MDA-MB-468 & KSP11 & DNA replication \\
Ibrutinib & A565 & Pyrimidine antimetabolite & Other, kinases \\
IGF1R_3801 & A565 & BTK & IGF1R signaling \\
Lapatinib & MDA-MB-468 & IGFR1 & EGFR signaling \\
\hline
\end{tabular}


Table 3. Cont.

\begin{tabular}{|c|c|c|c|}
\hline Drug Name & Cell Lines & Putative Target & Pathway Name \\
\hline MG-132 & $\begin{array}{c}\text { A565, HCC1143, HCC1937, } \\
\text { HCC70, MDA-MB-468 }\end{array}$ & Proteasome, CAPN1 & $\begin{array}{c}\text { Protein stability and } \\
\text { degradation }\end{array}$ \\
\hline Pevonedistat & HCC70 & NAE & Other \\
\hline Sabutoclax & MDA-MB-468 & BCL2, BCL-XL, BFL1, MCL1 & Apoptosis regulation \\
\hline Sepantronium bromide & $\begin{array}{l}\text { HCC1143, HCC1395, } \\
\text { HCC1937, HCC70, } \\
\text { MDA-MB-468 }\end{array}$ & BIRC5 & Apoptosis regulation \\
\hline Staurosporine & $\begin{array}{c}\text { A565, HCC1143, HCC1937, } \\
\text { HCC70, MDA-MB-468 }\end{array}$ & $\begin{array}{l}\text { Broad-spectrum kinase } \\
\text { inhibitor }\end{array}$ & RTK signaling \\
\hline Topotecan & MDA-MB- 468 & - & DNA replication \\
\hline ULK1_4989 & HCC70, MDA-MB-468 & ULK1 & Other, kinases \\
\hline Vinblastine & HCC1395 & Microtubule destabilizer & Mitosis \\
\hline Vincristine & A565, MDA-MB-468 & - & Mitosis \\
\hline Vinorelbine & A565 & Microtubule destabilizer & Mitosis \\
\hline
\end{tabular}

\section{Discussion}

\subsection{Importance of Combining Database Information and Cell Lines}

Databases serve as preliminary approaches in preclinical in vitro and in vivo assays to address inquiries regarding pathogenicity and drug candidates. For this study, the TCGA and METABRIC databases were analyzed to identify frequent variants in DNA repair genes in YWBC. In addition, using these tools we were able to compare reported variants in different age groups from LA countries.

On the other hand, in vitro studies with cancer cell lines remain relevant for advancing clinical cancer research because they resemble molecular characteristics and allow analyses on therapy response in drug evaluation. In addition, they are an important tool to perform large-scale drug sensitivity assays and interactions among drugs and genes, which are fundamental in Precision Medicine. These studies are unbiased for exploring alleged factors of drug sensitivity [23]. Cancer therapy approaches are being improved by new technologies capturing the clinical and molecular profiles of a patient and allow statistical assessment against impressive sets of information stored in public databases [28].

\subsection{Analysis of Pathogenic Variants of YWBC in LA and Public Databases}

The analysis performed in the METABRIC and TCGA databases shows that there is a significant presence of young women $<50$ years of age in both databases. It is observed that different subtypes of $\mathrm{BC}$ predominate in each age group, such as basal and luminal $\mathrm{A}$, in patients in the 25-30-year-old group. Remarkably, survival analysis shows that young women between the ages of 25 and 35 have the lowest survival rates. This group includes a 21-year-old woman registered in the METABRIC database. DNA repair genes that are frequently altered in both METABRIC and TCGA include TP53, ATR, and FANCA.

As expected, mutational load analysis shows accumulation of mutations as a function of aging. Unfortunately, there is an underrepresentation of YWBC from LA in the METABRIC (no patients) and TCGA (11 patients) studies to corroborate this assertion. According to Wojtyla et al., BC death rates are not decreasing in LA countries. For women aged 20-49 years, low mortality rates are observed only in Chile and Cuba, while an increase in mortality is observed in the rest of the LA countries [36]. Although the incidence of $\mathrm{BC}$ is higher in the US and European populations, the mortality-incidence ratio is higher for LA, as described by Dutil et al. [37]

Another observation from this study is that the mutational profile of many populations from LA is limited, as concluded by Ren at al. [38]. We observed that the DNA repair gene variants reported in LA are not well represented in commercial BC cell lines, so this issue needs to be addressed. Furthermore, variants without defined pathogenicity abound in patients from the region, and since these variants are not represented in $\mathrm{BC}$ cell lines, the functional analysis of DNA repair pathways is troublesome. Some methodologies, such as 
CRISPR/Cas9 edition [39,40], or the analysis of established patient-derived cell lines, can be used to perform studies to define the pathogenicity of these particular variants.

\subsection{Drugs with Reported Sensitivity in BC Cell Lines}

In this study, 27 drugs were identified with effect in six BC cell lines (AU565, HCC1143, HCC1395, HCC1937, HCC70, and MDA-MB-468). In addition, according to CIVIC database there are no FDA-approved or NCCN-compendium register treatments especially for patients that carry some of the LA reported variants such as R248Q variant for TP53, since this variant has been correlated with worse overall survival in BC patients in contrast to wild-type [41,42].

Some drugs are being tested in clinical trials, others are still being assessed in preclinical models, particularly in cultured lines. Information for some drugs was either scarce or null. Among these, sepantronium bromide (YM-155) targets the survivin protein inducing anti-apoptotic capacity. Preclinical and phase I clinical trials reported promising results, nonetheless, a poor performance was observed in phase II clinical trials for different cancer types. Wani et al. developed a BC cell line (MCF-7) expressing resistance to YM-155 and observed that continuous treatment with YM155 resulted in a low expression of survivin. This compound confers its chemotherapeutic effect by causing oxidative stress-mediated DNA damage. Therefore, DNA damage-response pathway proteins will be appropriate predictive biomarkers of YM155 response in these cells [43]. Mazzio et al. treated MDA-MB-231 BC cells with YM155 and observed changes in survivin mRNA and protein levels. Findings suggest that YM-155 inactivates replication-dependent DNA repair systems. They reported upregulation of SIK1 and FOSB (tumor suppressors), KDM6B (histone methylation), and NOCT, PER, BHLHe40, and NFIL (circadian rhythm). Conversely, downregulation of GUSBP3 (glucuronidase), some micro-RNAs, and DNA damage repair players like $C E N P I, P O L Q, R A D 54 B$ was also observed. The most affected pathways were ATM/FANC (FANC2, FANCI, BRCA1, BRCA2, RAD51, PALB2) and ATR [44].

Moreover, for the acetalax drug, Rajapaske et al. propose repositioning acetalax as an anticancer drug candidate for triple-negative BC based on their cytotoxic and antiproliferative activities in BC cell lines [45]. Similar findings were reported by Morrison and collaborators [46].

A study conducted by Hennessy et al. with AZD5582 showed apoptosis induction in BC MDA-MB-231 cell line at subnanomolar concentrations characterized by cIAP1 degradation. These observations were corroborated in xenograft-bearing mice implanted with MDA-MB-231, in which tumor regression was achieved and molecular analyses confirmed the degradation of cIAP1 this compound is being considered as a candidate for clinical trials [47]. Similarly, Polanski et al. conducted a combined screening employing $31 \mathrm{BC}$ cell lines and demonstrated synergy between TRAIL and AZD5582 in approximately $30 \%$ of tested cell lines. This effect was correlated with sensitivity to TRAIL, but not to AZD5582 as a single agent. Most of AZD5582 + TRAIL-resistant BC cell lines preserving a functional death route were sensitive to AZD5582 + TNF $\alpha$ combination treatment [48].

AZD7762 (DN10764), a selective inhibitor of checkpoint kinases 1 and 2, has been reported as useful to suppress BC metastasis. Park et al. observed that this compound inhibited cell proliferation and GAS6-mediated AXL signaling, resulting in reduced invasion and migration capabilities. It has been shown that this drug promotes caspase $3 / 7$ apoptosis in BC cells. Similar results were observed in in vivo metastasis models. This study suggests that combined therapy strategies targeting AXL, like AZD7763, could improve responses in drug-resistant solid tumors where AXL is involved, such as NSCLC, BC, ovarian cancer, and others [49]. Moreover, Min et al. demonstrated synergism between gemcitabine (GEM) and AZD7762 in a TNBC cell line [50].

Alsamman et al. examined an approach to overcome cisplatin resistance using staurosporine in breast, colon, and ovarian cancer cell lines by evaluating proliferation, morphology, and p62 levels after one of three treatments (cisplatin, staurosporine, or both combined). Results showed an elevation of p62 levels after cisplatin treatment. On the 
contrary, a reduction of p62 level was reported after staurosporine treatment. These results propose that cancer cells could be sensitized to cisplatin using staurosporine by downregulation of p62 [51].

Some combination therapies are studied and used in selected cancer types such as TNBC and NSCLC. These therapies show benefits and promising results, yet the disadvantages of treatments like doxorubicin against TNBC and NSCLC are toxicity and resistance. Studies conducted by Ghosh et al. explored a combined therapy with doxorubicin and vincristine for these cancer types, optimizing a single PEGylated liposomal formulation. A significant reduction $(p<0.05)$ of IC50 and cell viability of cell lines A549 (NSCLC) and MDA-MB-231 (BC) was observed compared with single drug treatments. This observation was corroborated in in vivo studies showing enhanced tumor reduction after vincristine plus doxorubicin therapy $[52,53]$.

According to Falchook et al., alisertib (MLN8237), a selective Aurora A Kinase (AAK) inhibitor, shows good antitumor and AAK inhibitor activity in xenograft models consisting of different tumor types. This compound exhibited antitumor activity at an oral dose of $40 \mathrm{mg}$ twice daily plus weekly paclitaxel $60 \mathrm{mg} / \mathrm{m}^{2}$ in patients with ovarian cancer. Therefore, future studies of alisertib in combination with taxanes and paclitaxel are expected [54]. Alisertib did not perform as expected as a single agent in phase III trials, but there is a clinical trial phase I (NCT02219789) evaluating its combination with fulvestrant [55]. It has been suggested that the combination of Alisterib with other agents may reduce the toxicity of anticancer drugs, increasing their anticancer effects [56].

In a study conducted by $\mathrm{Li}$ et al., docetaxel was evaluated in combination with lobaplatin versus docetaxel combined with gemcitabine for treatment in 26 patients with recurrent metastatic $\mathrm{BC}$ for each treatment group. Lobaplatin is a dual inhibitor targeting EGFR and HER2 which do not show cross-resistance with cisplatin and this combination is effective in BC. Gemcitabine has also shown certain effects in recurrent metastatic BC. Complete remission was observed in five patients $(11.6 \%)$, three patients with docetaxel and lobaplatin and two patients with combined therapy of docetaxel and gemcitabine, and partial response in 16 patients $(37.2 \%)$. Reported response rates of the groups were comparable $(47.6 \%, 50.0 \%)$. Median survival times after relapse and metastasis of the docetaxel and gemcitabine group were 25 months, whereas the docetaxel and lobaplatin group reported 18 months. Similar results were observed for median progression-free survival after relapse and metastasis. Therefore, researchers concluded that these combinations are effective and tolerable for advanced BC [57]. Similarly, alternative combination therapy for HER2-negative BC of docetaxel and cyclophosphamide (TC) was assessed by Caparica and collaborators in a meta-analysis, compared six cycles of this combined therapy versus an anthracycline and taxane-based regimen $(\mathrm{A}+\mathrm{T})$ in the adjuvant treatment of HER2negative BC. As a result, they conclude that for adjuvant treatment in this subtype of BC, $\mathrm{A}+\mathrm{T}$ treatment was associated with more toxicity risks and no clear survival benefit when compared with six cycles of TC. Therefore, they considered that A + T may be more beneficial for patients with higher risk, whereas for patients with lower risk TC combination therapy may be an effective and lower toxic alternative [58].

A study conducted by Lin et al. [59] in lung cancer, suggests that dactinomycin upregulates p53, and lung cancer cells (A549) result in growth suppression and apoptosis. Similarly, a study conducted by Das et al. reported this drug as a potential anti-BC agent using an in vivo-like 3D cell culture system for identification and validation of anti-cancer agents. Herein, it was shown that actinomycin D targets Sox-2, a stem cell transcription factor, and downregulates its expression resulting in a reduction of stem-cell population and stalling of the tumor progression initiation [60].

Sinha and collaborators evaluated topotecan effects in MCF-7 BC cells. The study reported that reactive free radical species are key players in cancer cell death. Topotecan significantly downregulates the estrogen receptor alpha (ER /ESR1) and the BCL2 genes [61]. In addition, studies such as that conducted by Guo et al. explore the combination of topotecan with other agents like daidzein, a phytoestrogen in vitro. Results showed strong 
synergistic effects on MCF7 cells by arresting the G2/M cell cycle phase and inducing apoptosis [62].

Hu et al. tested sabutoclax, a BCL-2 protein family antagonist, in two chemoresistant $\mathrm{BC}$ cell lines in vitro and in vivo, showing a significant cytotoxic effect and elimination of the cancer stem cell-like subpopulation. These findings suggest that sabutoclax partially overcomes drug resistance by inducing apoptosis mediated by inhibition of BCL-2 family proteins. These results stimulate further studies to explore the efficacy of sabutoclax alone or in combination in BC patients with nonresponsive chemotherapy [63].

Dinaciclib, a cyclin-dependent kinase (CDK) 1/2/5/9 inhibitor, has shown encouraging results in preclinical studies and is being evaluated in phase I clinical trials for BC treatment [64]. In a study conducted by Johnson et al., dinaciclib reported activity against CDK12, a regulator for transcription in HR, as well as previously mentioned CDKs. They observed that this drug reverses resistance to PARPi and eliminates HR repair in TNBC cells and xenografts derived from patients with mutated BRCA. Therefore, these results underline the importance of blocking HR repair for therapeutic purposes, encouraging combination therapies for TNBC such as dinaciclib as CDK12 and PARP inhibitors [65]. Similarly, in a study conducted by Zhu et al., dinaciclib was reported to restore sensitivity to cisplatin in cells with resistance to tamoxifen [66]. Dinaciblin is currently in phase III clinical trials. In addition, Nie et al. reported that inhibition of CDK2/EZH2 restores the expression of estrogen receptor alpha $(E R \alpha)$ leading to tamoxifen in vitro and in vivo sensitivity [67]. On the other hand, no information was found for drugs like AZD5991, CDK9_5038, CDK9_5576, Dihydrorotenone, Eg5_9814, IGF1R_3801, ULK1_4989, and Vinblastine for BC therapy.

Furthermore, one limitation of this study is that there are few studies reporting DNA repair variants in YWBC in LA countries, therefore variants representing this population are unknown. Another limitation of this study is that not all the variants reported are totally validated in public databases, some of them are reported as variants of unknown significance (VUS), hence, the effect of these variants needs to be studied. In addition, there are few BC cell lines that represent variants reported in LA.

\section{Materials and Methods}

For this study, 90 selected DNA repair genes were analyzed in BC databases such as TCGA, METABRIC, CCLE, and COSMIC Cell Lines. All this information was specific for women under 50 years old (y.o.), tumor sample data was analyzed for METABRIC and TCGA. For Latin American women, germline variants were considered. In addition, drug analyses were studied specifically for BC cell lines that represented DNA repair variants reported in LA YWBC (Figure 9).

\subsection{DNA Repair Genes of Interest}

For this study a selection of 90 genes were analyzed in different databases (Table 4). For this list, genes that participate in DNA repair pathways such as homologous recombination, non-homologous end joining, base excision repair, nucleotide excision repair and mismatch repair, were considered. In addition, this list includes genes that perform in the cell cycle and are involved in DNA repair mechanisms [13,21,68-71]. 


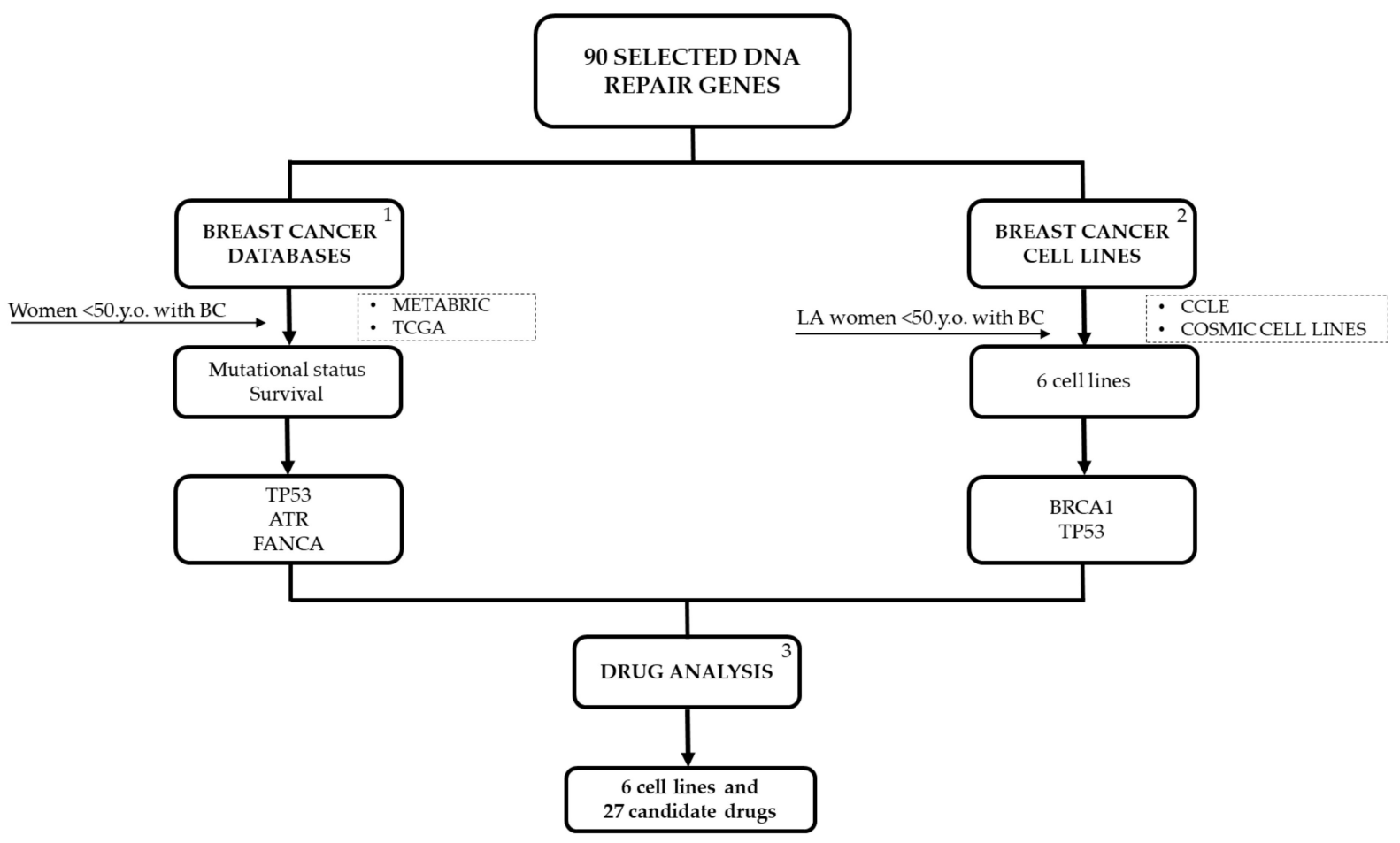

Figure 9. Flow chart followed in this study. (1) For further details refer to Figure 2; (2) for further details refer to Figure 5; (3) for further details refer to Figure 7. CCLE, Cancer Cell Line Encyclopedia; METABRIC, Molecular Taxonomy of Breast Cancer International Consortium; TCGA, The Cancer Genome Atlas.

Table 4. Selection of DNA repair genes for this study.

\begin{tabular}{ccccc}
\hline APEX1 & CHEK2 & LIG4 & POLD2 & SSBP1 \\
ATM & CTiP & MDC1 & POLE & STK11 \\
ATR & DNTT & MLH1 & POLH & STRA13 \\
BARD1 & ERCC3 & MLH3 & POLQ & TIMELESS \\
BLM & ERCC6 & MRE11A & PP4C & TOP2A \\
BRCA1 & EXO1 & MSH2 & PRKDC & TOP3A \\
BRCA2 & FAM175A & MSH3 & RAD50 & TOPBP1 \\
BRIP1 & FANCA & MSH6 & RAD51 & TP53 \\
CCNA2 & FANCB & MUTYH & RAD51C & TP53BP1 \\
CCNB1 & FANCC & NBN & RAD51D & TRIP13 \\
CCNB2 & FANCD2 & NEIL2 & RAD52 & UBE2T \\
CDC25A & FANCI & NHEJ1 & RECQL4 & UIMC1 \\
CDK1 & FANCL & PALB2 & REV3L & WRN \\
CDK12 & FANCM & PARP1 & RIF1 & XPA \\
CDK4 & GADD45B & PARP2 & RPA1 & XPC \\
CDKN2A & GEN1 & PARPBP & RPA2 & XRCC1 \\
CENPS & H2AFX & PCNA & RRM2 & XRCC5 \\
CHEK1 & HDAC2 & PMS2 & SMC1A & XRCC6 \\
\hline
\end{tabular}

\subsection{Young Women with BC Tumor Sample Data}

Data was retrieved from TCGA and METABRIC from https: / / www.cbioportal.org/ accessed on 23 March 2021, selecting patients under 50 years old at diagnosis for further analysis. A total of 2509 samples were obtained from METABRIC, for the purpose of this study only samples of patients under 50 years were selected. A total of 567 samples from METABRIC were used to complete further analyses. From the TCGA database, a total of 1084 samples were retrieved. Considering the selection criteria of women under 50 years, 292 samples were chosen for further analyses. Later, a search for 90 DNA repair genes was made to obtain data of frequently altered genes and information concerning age at diagnosis and other clinical data such as BC type and survival from these samples. 


\subsection{BC Cell Lines Selection and Mutation Analysis for DNA Repair Genes}

Data for a panel of 52 human BC cell lines was obtained from The Catalog of Somatic Mutations in Cancer (COSMIC) Cell Line Project database, and 69 BC cell lines from The Cancer Cell Line Encyclopedia (CCLE). In Table S3 a list of retrieved cell lines is noted along with $B C$ subtypes $[22,72-77]$ as well as reported mutations in DNA repair genes. Complete mutation data was obtained from https:/ / cancer.sanger.ac.uk/cell_lines/download (last accessed on 21 November 2021), data file was filtered by cancer type, BC and analyzed. For CCLE, https:/ / portals.broadinstitute.org/ccle (last accessed on 21 November 2021), the CCLE_DepMap_18q3_maf_20180718.txt/merged mutation calls (coding region, germline filtered) data was analyzed for this study. A total of 227,855 mutations were retrieved from COSMIC BC cell lines. Following, this data was filtered searching for the 90 DNA repair genes selected, to identify all the cell lines harboring mutations in one or more of these genes obtaining 2335 reported mutations in $52 \mathrm{BC}$ cell lines for 84 DNA repair genes. In addition, for CCLE, a total of 35,590 mutations were obtained for BC cell lines. After selecting mutations for the 90 DNA repair genes 274 mutations remained for 74 genes in 65 cell lines. Furthermore, an analysis was performed to identify cell lines that presented frequent DNA repair variants observed in young women with BC. This selection will be useful to implement further in vitro analysis of candidate cell lines with altered DNA repair genes and evaluate drug sensitivity.

\subsection{Drug Variant Sensitivity}

Data from databases was analyzed aiming to spot drug sensitivity, half maximal inhibitory concentration (IC50), in BC cell lines with altered DNA repair genes. Information for drug-gene interaction was obtained from The Drug Interaction DataBase (DGIdb) (http:/ /www.dgidb.org/search_interactions, last accessed on 21 November 2021) [30] and The Genomics of Drug Sensitivity in Cancer Project (https://www.cancerrxgene. org/, last accessed on 21 November 2021), a database to find drug response and genomic markers of sensitivity. In addition, Clinical Interpretation of Variants in Cancer (CIVIC) (https: / / civicdb.org/home, last accessed on 21 November 2021) and Drugbank (https: / / www.drugbank.ca/, last accessed on 21 November 2021) databases were used to gather supporting data for reported variants with drug sensitivity in previously mentioned databases. The Drugbank database is a bioinformatics resource that provides drug data combined with target information.

\subsection{Reported DNA Repair Variants for YWBC from $L A$}

A comparative analysis took place between frequent reported variants observed in YWBC from LA countries [32,78] and reported variants from databases such as TCGA, METABRIC, COSMIC, and CCLE. Variant selection for this study is shown in Figure 10. Table S1 contains all variants reported for DNA repair genes along with their effect reported by ClinVar, COSMIC, and PolyPhen. Information regarding BC subtype was available only for $20 \%$ of all the reported variants (Table S2). 


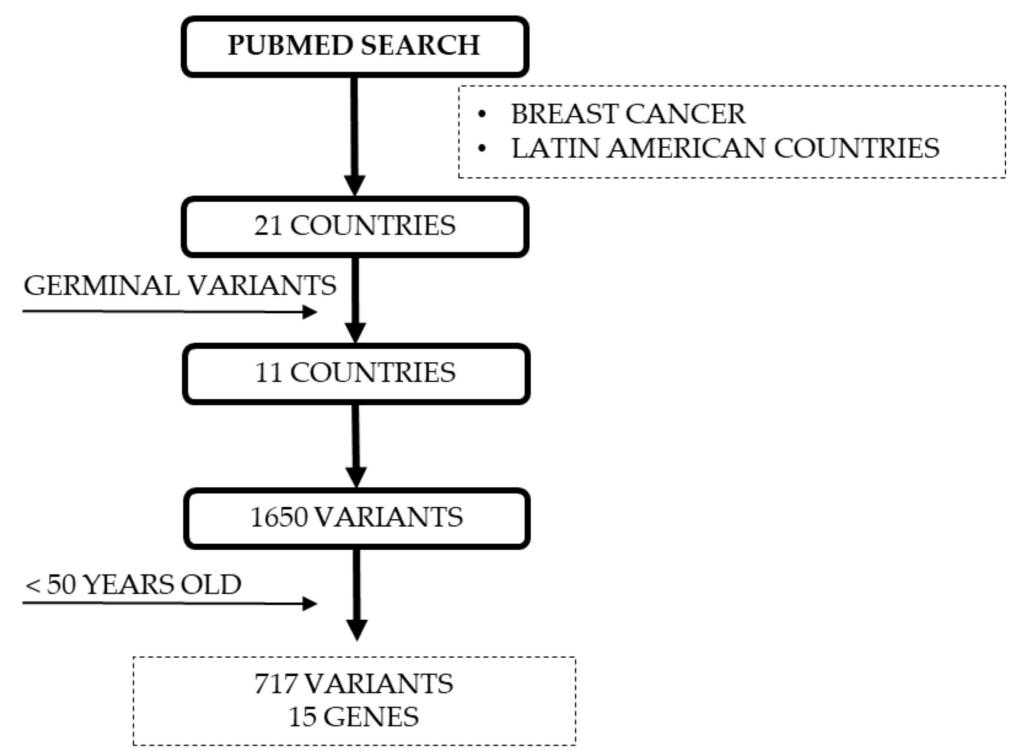

Figure 10. Variants selection for this study. Considering our previous study, a PUBMED search was performed for BC and LA countries. Herein, 11 out of 21 countries reported germline variants with a total of 1650 variants. After selecting only variants with reported age-onset under 50 years old, 717 variants remained for 15 genes. This database was used for this study.

\section{Conclusions}

There is vast information supporting the participation of DNA repair genes in BC and their possible implication in predisposition, development, outcome, and therapy response. Even though there is a wide range of publicly databases and studies addressing DNA repair variants, the representation for populations such as the Latin-American is minor and in contrast with other regions of the world reported data is limited. For the METABRIC and TCGA study there was an underrepresentation of YWBC from LA countries. Added to that, $\mathrm{BC}$ cell lines do not represent frequent DNA repair variants reported in countries from our region. Therefore, there is an opportunity area to address this matter.

The use of cell lines is fundamental for drug analysis, along with cell lines databases for preliminary studies. Herein, comparing LA-reported DNA repair variants from women $<50$ y.o. with $B C$ cell lines resulted in a minor representation of these variants observing only seven $B C$ cell lines for BRCA1 and TP53 genes. In addition, from the 15 DNA repair genes identified in young women $<50$ y.o. in LA, there are no BC cell lines that carry variants for 13 of those genes. Therefore, it represents a challenge to study these variants reported in the LA region and their research focusing on preliminary drug assays.

\section{Take Home Messages}

- Of our selection of 90 genes participating in DNA repair mechanisms, no representativeness of variants reported in LA was observed for $\mathrm{YWBC}<50$ y.o., compared to variants from other populations.

- Cell line database analyses resulted in few variants representation of YWBC from LA countries in BC cell lines.

- More studies for LA population are needed to approach DNA repair genes and mechanisms for YWBC besides BRCA1, BRCA2, and TP53 to generate cell lines that represent variants for this population.

- Our analyses resulted in different candidate drugs, nevertheless, not all of these drugs are validated in clinical practice.

Supplementary Materials: The following are available online at https:/ / www.mdpi.com/article / $10.3390 /$ ijms222313030/s1. 
Author Contributions: Conceptualization, R.O.-L., E.M.-L., A.R.-M. and L.K.U.-J.; methodology, L.K.U.-J., E.M.-L. and R.O.-L.; software, L.K.U.-J. and E.M.-L.; validation, L.K.U.-J. and E.M.-L.; formal analysis, L.K.U.-J.; investigation, L.K.U.-J.; resources, E.M.-L. and F.R.R.-R.; data curation, L.K.U.-J.; writing—original draft preparation, L.K.U.-J.; writing—review and editing, E.M.-L., R.O.-L. and A.R.-M.; visualization, E.M.-L., A.R.-M. and R.O.-L.; supervision, R.O.-L.; project administration, R.O.-L. All authors have read and agreed to the published version of the manuscript.

Funding: This research received no external funding.

Acknowledgments: This work was supported by Tecnologico de Monterrey, Escuela de Medicina y Ciencias de la Salud, Cancer Research Group, as well as a Ph.D. scholarship granted to U.-J.L.K. (CVU \#883312) by CONACyT (Mexican Council for Science and Technology).

Conflicts of Interest: The authors declare no conflict of interest.

\section{References}

1. Bray, F.; Ferlay, J.; Soerjomataram, I.; Siegel, R.L.; Torre, L.A.; Jemal, A. Global Cancer Statistics 2018: GLOBOCAN Estimates of Incidence and Mortality Worldwide for 36 Cancers in 185 Countries: Global Cancer Statistics 2018. Cancer J. Clin. 2018, 68, 394-424. [CrossRef]

2. Merino Bonilla, J.A.; Torres Tabanera, M.; Ros Mendoza, L.H. Breast Cancer in the 21st Century: From Early Detection to New Therapies. Radiologia 2017, 59, 368-379. [CrossRef] [PubMed]

3. Ogiya, R.; Sagara, Y.; Niikura, N.; Freedman, R.A. Impact of Subtype on Survival of Young Patients with Stage IV Breast Cancer. Clin. Breast Cancer 2019, 19, 200-207. [CrossRef] [PubMed]

4. Rosenberg, S.M.; Greaney, M.L.; Patenaude, A.F.; Partridge, A.H. Factors Affecting Surgical Decisions in Newly Diagnosed Young Women with Early-Stage Breast Cancer. J. Adolesc. Young Adult Oncol. 2019, 8, 463-468. [CrossRef] [PubMed]

5. Johnson, R.H.; Anders, C.K.; Litton, J.K.; Ruddy, K.J.; Bleyer, A. Breast cancer in adolescents and young adults. Pediatr. Blood Cancer 2018, 65, e27397. [CrossRef]

6. Mealey, N.E.; O'Sullivan, D.E.; Pader, J.; Ruan, Y.; Wang, E.; Quan, M.L.; Brenner, D.R. Mutational landscape differences between young-onset and older-onset breast cancer patients. BMC Cancer 2020, 20, 212. [CrossRef]

7. Poggio, F.; Lambertini, M.; Bighin, C.; Conte, B.; Blondeaux, E.; D’Alonzo, A.; Dellepiane, C.; Boccardo, F.M.; Del Mastro, L. Management of young women with early breast cancer. ESMO Open 2018, 3, e000458. [CrossRef]

8. Peña-Chilet, M.; Martínez, M.T.; Pérez-Fidalgo, J.A.; Peiró-Chova, L.; Oltra, S.S.; Tormo, E.; Alonso-Yuste, E.; Martinez-Delgado, B.; Eroles, P.; Climent, J.; et al. MicroRNA profile in very young women with breast cancer. BMC Cancer 2014, 14, 529. [CrossRef]

9. Anastasiadi, Z.; Lianos, G.D.; Ignatiadou, E.; Harissis, H.V.; Mitsis, M. Breast cancer in young women: An overview. Updates Surg. 2017, 69, 313-317. [CrossRef] [PubMed]

10. Hironaka-Mitsuhashi, A.; Tsuda, H.; Yoshida, M.; Shimizu, C.; Asaga, S.; Hojo, T.; Tamura, K.; Kinoshita, T.; Ushijima, T.; Hiraoka, N.; et al. Invasive breast cancers in adolescent and young adult women show more aggressive immunohistochemical and clinical features than those in women aged 40-44 years. Breast Cancer 2018, 26, 386-396. [CrossRef]

11. Lee, K.J.; Piett, C.G.; Andrews, J.F.; Mann, E.; Nagel, Z.D.; Gassman, N.R. Defective base excision repair in the response to DNA damaging agents in triple negative breast cancer. PLoS ONE 2019, 14, e0223725. [CrossRef] [PubMed]

12. Trenner, A.; Sartori, A.A. Harnessing DNA Double-Strand Break Repair for Cancer Treatment. Front. Oncol. 2019, 9, 1388. [CrossRef]

13. Gilmore, E.; McCabe, N.; Kennedy, R.D.; Parkes, E.E. DNA Repair Deficiency in Breast Cancer: Opportunities for Immunotherapy. Available online: https:/ / www.hindawi.com/journals/jo/2019/4325105/ (accessed on 4 July 2019).

14. Kleiblova, P.; Stolarova, L.; Krizova, K.; Lhota, F.; Hojny, J.; Zemankova, P.; Havranek, O.; Vocka, M.; Cerna, M.; Lhotova, K.; et al. Identification of deleterious germline CHEK2 mutations and their association with breast and ovarian cancer. Int. J. Cancer 2019, 145, 1782-1797. [CrossRef]

15. Gómez-Flores-Ramos, L.; Castro-Sanchez, A.; Peña-Curiel, O.; Mohar-Betancourt, A. Molecular Biology in Young Women With Breast Cancer: From Tumor Gene Expression To Dna Mutations. Rev. Investig. Clin. 2017, 69, 181-192. [CrossRef] [PubMed]

16. Grešner, P.; Jablonska, E.; Gromadzińska, J. Rad51 paralogs and the risk of unselected breast cancer: A case-control study. PLoS ONE 2020, 15, e0226976. [CrossRef]

17. Gentles, L.; Goranov, B.; Matheson, E.; Herriott, A.; Kaufmann, A.; Hall, S.; Mukhopadhyay, A.; Drew, Y.; Curtin, N.J.; O'Donnell, R. Exploring the Frequency of Homologous Recombination DNA Repair Dysfunction in Multiple Cancer Types. Cancers 2019, 11, 354. [CrossRef] [PubMed]

18. Zhao, Y.; Chen, S. Targeting DNA Double-Strand Break (DSB) Repair to Counteract Tumor Radio-resistance. Curr. Drug Targets 2019, 20, 891-902. [CrossRef] [PubMed]

19. Riaz, N.; Blecua, P.; Lim, R.S.; Shen, R.; Higginson, D.; Weinhold, N.; Norton, L.; Weigelt, B.; Powell, S.N.; Reis-Filho, J.S. Pancancer analysis of bi-allelic alterations in homologous recombination DNA repair genes. Nat. Commun. 2017, 8, 857. [CrossRef] [PubMed] 
20. Sonnenblick, A.; Zick, A.; Maoz, M.; Cohen, S.; Kadouri, L.; Peretz, T.; Hubert, A. Defects in homologous recombination repair genes are associated with good prognosis and clinical sensitivity to DNA-damaging agents in pancreatic cancer: A case report. Mol. Clin. Oncol. 2018, 8, 683-685. [CrossRef] [PubMed]

21. Wang, Y.; Ung, M.H.; Cantor, S.; Cheng, C. Computational Investigation of Homologous Recombination DNA Repair Deficiency in Sporadic Breast Cancer. Sci. Rep. 2017, 7, 15742. [CrossRef]

22. Dai, X.; Cheng, H.; Bai, Z.; Li, J. Breast Cancer Cell Line Classification and Its Relevance with Breast Tumor Subtyping. J. Cancer 2017, 8, 3131-3141. [CrossRef] [PubMed]

23. Iorio, F.; Knijnenburg, T.A.; Vis, D.J.; Bignell, G.R.; Menden, M.P.; Schubert, M.; Aben, N.; Gonçalves, E.; Barthorpe, S.; Lightfoot, H.; et al. A Landscape of Pharmacogenomic Interactions in Cancer. Cell 2016, 166, 740-754. [CrossRef]

24. Zhang, F.; Wang, M.; Xi, J.; Yang, J.; Li, A. A novel heterogeneous network-based method for drug response prediction in cancer cell lines. Sci. Rep. 2018, 8, 3355. [CrossRef]

25. Jastrzebski, K.; Thijssen, B.; Kluin, R.J.; De Lint, K.; Majewski, I.J.; Beijersbergen, R.L.; Wessels, L.F. Integrative Modeling Identifies Key Determinants of Inhibitor Sensitivity in Breast Cancer Cell Lines. Cancer Res. 2018, 78, 4396-4410. [CrossRef] [PubMed]

26. Yao, F.; Tonekaboni, S.A.M.; Safikhani, Z.; Smirnov, P.; El-Hachem, N.; Freeman, M.; Manem, V.S.K.; Haibe-Kains, B. Tissue specificity of in vitro drug sensitivity. J. Am. Med. Inform. Assoc. 2017, 25, 158-166. [CrossRef] [PubMed]

27. Kim, S.; Sundaresan, V.; Zhou, L.; Kahveci, T. Integrating Domain Specific Knowledge and Network Analysis to Predict Drug Sensitivity of Cancer Cell Lines. PLoS ONE 2016, 11, e0162173. [CrossRef] [PubMed]

28. Wei, D.; Liu, C.; Zheng, X.; Li, Y. Comprehensive anticancer drug response prediction based on a simple cell line-drug complex network model. BMC Bioinform. 2019, 20, 44. [CrossRef] [PubMed]

29. Olsson, E.; Winter, C.; George, A.; Chen, Y.; Törngren, T.; Bendahl, P.-O.; Borg, A.; Gruvberger-Saal, S.K.; Saal, L.H. Mutation Screening of 1,237 Cancer Genes across Six Model Cell Lines of Basal-Like Breast Cancer. PLoS ONE 2015, 10, e0144528. [CrossRef]

30. Lodovichi, S.; Mercatanti, A.; Cervelli, T.; Galli, A. Computational analysis of data from a genome-wide screening identifies new PARP1 functional interactors as potential therapeutic targets. Oncotarget 2019, 10, 2722-2737. [CrossRef]

31. Liu, Q.; Yao, S.; Zhao, H.; Hu, Q.; Kwan, M.L.; Roh, J.M.; Ambrosone, C.B.; Kushi, L.H.; Liu, S.; Zhu, Q. Early-onset triple-negative breast cancer in multiracial/ethnic populations: Distinct trends of prevalence of truncation mutations. Cancer Med. 2019, 8, 1845-1853. [CrossRef]

32. Urbina-Jara, L.K.; Martinez, R.; Martinez-Ledesma, E.; Aguilar, D.; Villarreal-Garza, C.; Ortiz-Lopez, R.; Jara, U.; Ledesma, M.; Garza, V.; Lopez, O.; et al. Landscape of Germline Mutations in DNA Repair Genes for Breast Cancer in Latin America: Opportunities for PARP-Like Inhibitors and Immunotherapy. Genes 2019, 10, 786. [CrossRef]

33. Cerami, E.; Gao, J.; Dogrusoz, U.; Gross, B.E.; Sumer, S.O.; Aksoy, B.A.; Jacobsen, A.; Byrne, C.J.; Heuer, M.L.; Larsson, E.; et al. The CBio Cancer Genomics Portal: An Open Platform for Exploring Multidimensional Cancer Genomics Data. Cancer Discov. 2012, 2, 401-404. [CrossRef] [PubMed]

34. Gao, J.; Aksoy, B.A.; Dogrusoz, U.; Dresdner, G.; Gross, B.; Sumer, S.O.; Sun, Y.; Jacobsen, A.; Sinha, R.; Larsson, E.; et al Integrative Analysis of Complex Cancer Genomics and Clinical Profiles Using the CBioPortal. Sci. Signal. 2013, 6, pl1. [CrossRef]

35. Spratt, D.E.; Chan, T.; Waldron, L.; Speers, C.; Feng, F.Y.; Ogunwobi, O.; Osborne, J.R. Racial/Ethnic Disparities in Genomic Sequencing. JAMA Oncol. 2016, 2, 1070-1074. [CrossRef] [PubMed]

36. Wojtyla, C.; Bertuccio, P.; Ciebiera, M.; La Vecchia, C. Breast Cancer Mortality in the Americas and Australasia over the Period 1980-2017 with Predictions for 2025. Biology 2021, 10, 814. [CrossRef]

37. Dutil, J.; Golubeva, V.; Pacheco-Torres, A.L.; Diaz-Zabala, H.J.; Matta, J.L.; Monteiro, A. The spectrum of BRCA1 and BRCA2 alleles in Latin America and the Caribbean: A clinical perspective. Breast Cancer Res. Treat. 2015, 154, 441-453. [CrossRef] [PubMed]

38. Ren, M.; Orozco, A.; Shao, K.; Albanez, A.; Ortiz, J.; Cao, B.; Wang, L.; Barreda, L.; Alvarez, C.S.; Garland, L.; et al. Germline Variants in Hereditary Breast Cancer Genes Are Associated with Early Age at Diagnosis and Family History in Guatemalan Breast Cancer. Breast Cancer Res. Treat. 2021, 189, 533-539. [CrossRef] [PubMed]

39. Moyer, T.C.; Holland, A.J. Generation of a conditional analog-sensitive kinase in human cells using CRISPR/Cas9-mediated genome engineering. Methods Cell Biol. 2015, 129, 19-36. [CrossRef]

40. Gonzalez-Salinas, F.; Rojo, R.; Martinez-Amador, C.; Herrera-Gamboa, J.; Trevino, V. Transcriptomic and cellular analyses of CRISPR/Cas9-mediated edition of FASN show inhibition of aggressive characteristics in breast cancer cells. Biochem. Biophys. Res. Commun. 2020, 529, 321-327. [CrossRef] [PubMed]

41. Brachova, P.; Thiel, K.W.; Leslie, K.K. The Consequence of Oncomorphic TP53 Mutations in Ovarian Cancer. Int. J. Mol. Sci. 2013, 14, 19257-19275. [CrossRef] [PubMed]

42. Olivier, M.; Langerød, A.; Carrieri, P.; Bergh, J.; Klaar, S.; Eyfjord, J.; Theillet, C.; Rodriguez, C.; Lidereau, R.; Bièche, I.; et al. The clinical value of somatic TP53 gene mutations in 1,794 patients with breast cancer. Clin. Cancer Res. 2006, 12, $1157-1167$. [CrossRef]

43. Wani, T.; Surendran, S.; Mishra, V.S.; Chaturvedi, J.; Chowdhury, G.; Chakrabarty, A. Adaptation to chronic exposure to sepantronium bromide (YM155), a prototypical survivin suppressant is due to persistent DNA damage-response in breast cancer cells. Oncotarget 2018, 9, 33589-33600. [CrossRef] [PubMed] 
44. Mazzio, E.A.; Lewis, C.A.; Elhag, R.; Soliman, K.F. Effects of Sepantronium Bromide (YM-155) on the Whole Transcriptome of MDA-MB-231 Cells: Highlight on Impaired ATR/ATM Fanconi Anemia DNA Damage Response. Cancer Genom. Proteom. 2018, 15, 249-264. [CrossRef]

45. Rajapakse, V.N.; Luna, A.; Yamade, M.; Loman, L.; Varma, S.; Sunshine, M.; Iorio, F.; Sousa, F.G.; Elloumi, F.; Aladjem, M.I.; et al. CellMinerCDB for Integrative Cross-Database Genomics and Pharmacogenomics Analyses of Cancer Cell Lines. iScience 2018, 10, 247-264. [CrossRef]

46. Morrison, B.L.; Mullendore, M.E.; Stockwin, L.H.; Borgel, S.; Hollingshead, M.G.; Newton, D.L. Oxyphenisatin acetate (NSC 59687) triggers a cell starvation response leading to autophagy, mitochondrial dysfunction, and autocrine TNF $\alpha$-mediated apoptosis. Cancer Med. 2013, 2, 687-700. [CrossRef] [PubMed]

47. Hennessy, E.J.; Adam, A.; Aquila, B.M.; Castriotta, L.M.; Cook, D.; Hattersley, M.; Hird, A.W.; Huntington, C.; Kamhi, V.M.; Laing, N.M.; et al. Discovery of a Novel Class of Dimeric Smac Mimetics as Potent IAP Antagonists Resulting in a Clinical Candidate for the Treatment of Cancer (AZD5582). J. Med. Chem. 2013, 56, 9897-9919. [CrossRef] [PubMed]

48. Polanski, R.; Vincent, J.; Polanska, U.M.; Petreus, T.; Tang, E.K.Y. Caspase-8 activation by TRAIL monotherapy predicts responses to IAPi and TRAIL combination treatment in breast cancer cell lines. Cell Death Dis. 2015, 6, e1893. [CrossRef] [PubMed]

49. Park, J.-S.; Lee, C.; Kim, H.-K.; Kim, D.; Son, J.B.; Ko, E.; Cho, J.-H.; Kim, N.-D.; Nan, H.-Y.; Kim, C.-Y.; et al. Suppression of the metastatic spread of breast cancer by DN10764 (AZD7762)-mediated inhibition of AXL signaling. Oncotarget 2016, 7, 83308-83318. [CrossRef] [PubMed]

50. Min, D.-J.; He, S.; Green, J.E. Birinapant (TL32711) Improves Responses to GEM/AZD7762 Combination Therapy in Triplenegative Breast Cancer Cell Lines. Anticancer. Res. 2016, 36, 2649-2657. [PubMed]

51. Alsamman, K.; El-Masry, O.S. Staurosporine Alleviates Cisplatin Chemoresistance in Human Cancer Cell Models by Suppressing the Induction of SQSTM1/P62. Oncol. Rep. 2018, 40, 2157-2162. [CrossRef] [PubMed]

52. Ghosh, S.; Lalani, R.; Maiti, K.; Banerjee, S.; Patel, V.; Bhowmick, S.; Misra, A. Optimization and efficacy study of synergistic vincristine coloaded liposomal doxorubicin against breast and lung cancer. Nanomedicine 2020, 15, 2585-2607. [CrossRef]

53. Ghosh, S.; Lalani, R.; Maiti, K.; Banerjee, S.; Bhatt, H.; Bobde, Y.S.; Patel, V.; Biswas, S.; Bhowmick, S.; Misra, A. Synergistic co-loading of vincristine improved chemotherapeutic potential of pegylated liposomal doxorubicin against triple negative breast cancer and non-small cell lung cancer. Nanomed. Nanotechnol. Biol. Med. 2020, 31, 102320. [CrossRef]

54. Falchook, G.; Coleman, R.L.; Roszak, A.; Behbakht, K.; Matulonis, U.; Ray-Coquard, I.; Sawrycki, P.; Duska, L.R.; Tew, W.; Ghamande, S.; et al. Alisertib in Combination With Weekly Paclitaxel in Patients With Advanced Breast Cancer or Recurrent Ovarian Cancer. JAMA Oncol. 2019, 5, e183773. [CrossRef] [PubMed]

55. Shah, N.; Mohammad, A.S.; Saralkar, P.; Sprowls, S.A.; Vickers, S.D.; John, D.; Tallman, R.M.; Lucke-Wold, B.P.; Jarrell, K.E.; Pinti, M.; et al. Investigational chemotherapy and novel pharmacokinetic mechanisms for the treatment of breast cancer brain metastases. Pharmacol. Res. 2018, 132, 47-68. [CrossRef]

56. Zhang, W.; Xia, D.; Li, Z.; Zhou, T.; Chen, T.; Wu, Z.; Zhou, W.; Li, Z.; Li, L.; Xu, J. Aurora-A/ERK1/2/MTOR Axis Promotes Tumor Progression in Triple-Negative Breast Cancer and Dual-Targeting Aurora-A/MTOR Shows Synthetic Lethality. Cell Death Dis. 2019, 10, 606. [CrossRef] [PubMed]

57. Li, F.; Wang, B.; He, M.; Chang, J.; Li, J.; Shan, L.; Wang, H.; Hong, W.; Luo, D.; Song, Y.; et al. Pilot study of docetaxel combined with lobaplatin or gemcitabine for recurrent and metastatic breast cancer. Medicine 2019, 98, e18513. [CrossRef] [PubMed]

58. Caparica, R.; Bruzzone, M.; Poggio, F.; Ceppi, M.; de Azambuja, E.; Lambertini, M. Anthracycline and taxane-based chemotherapy versus docetaxel and cyclophosphamide in the adjuvant treatment of HER2-negative breast cancer patients: A systematic review and meta-analysis of randomized controlled trials. Breast Cancer Res. Treat. 2018, 174, 27-37. [CrossRef]

59. Lin, S.-Q.; Jia, F.-J.; Zhang, C.-Y.; Liu, F.-Y.; Ma, J.-H.; Han, Z.; Xie, W.-D.; Li, X. Actinomycin V Suppresses Human Non-Small-Cell Lung Carcinoma A549 Cells by Inducing G2/M Phase Arrest and Apoptosis via the p53-Dependent Pathway. Mar. Drugs 2019, 17, 572. [CrossRef] [PubMed]

60. Das, T.; Nair, R.R.; Green, R.; Padhee, S.; Howell, M.; Banerjee, J.; Mohapatra, S.S. Actinomycin D Down-regulates SOX2 Expression and Induces Death in Breast Cancer Stem Cells. Anticancer. Res. 2017, 37, 1655-1663. [CrossRef]

61. Sinha, B.K.; Tokar, E.J.; Bushel, P.R. Elucidation of Mechanisms of Topotecan-Induced Cell Death in Human Breast MCF-7 Cancer Cells by Gene Expression Analysis. Front. Genet. 2020, 11, 775. [CrossRef] [PubMed]

62. Guo, J.; Wang, Q.; Zhang, Y.; Sun, W.; Zhang, S.; Li, Y.; Wang, J.; Bao, Y. Functional daidzein enhances the anticancer effect of topotecan and reverses BCRP-mediated drug resistance in breast cancer. Pharmacol. Res. 2019, 147, 104387. [CrossRef] [PubMed]

63. Hu, Y.; Yagüe, E.; Zhao, J.; Wang, L.; Bai, J.; Yang, Q.; Pan, T.; Zhao, H.; Liu, J.; Zhang, J. Sabutoclax, pan-active BCL-2 protein family antagonist, overcomes drug resistance and eliminates cancer stem cells in breast cancer. Cancer Lett. 2018, 423, 47-59. [CrossRef]

64. Criscitiello, C.; Viale, G.; Esposito, A.; Curigliano, G. Dinaciclib for the treatment of breast cancer. Expert Opin. Investig. Drugs 2014, 23, 1305-1312. [CrossRef] [PubMed]

65. Johnson, S.F.; Cruz, C.; Greifenberg, A.K.; Dust, S.; Stover, D.; Chi, D.; Primack, B.; Cao, S.; Bernhardy, A.J.; Coulson, R.; et al. CDK12 Inhibition Reverses De Novo and Acquired PARP Inhibitor Resistance in BRCA Wild-Type and Mutated Models of Triple-Negative Breast Cancer. Cell Rep. 2016, 17, 2367-2381. [CrossRef] 
66. Zhu, Y.; Liu, Y.; Zhang, C.; Chu, J.; Wu, Y.; Li, Y.; Liu, J.; Li, Q.; Li, S.; Shi, Q.; et al. Tamoxifen-resistant breast cancer cells are resistant to DNA-damaging chemotherapy because of upregulated BARD1 and BRCA1. Nat. Commun. 2018, 9, 1595. [CrossRef] [PubMed]

67. Nie, L.; Wei, Y.; Zhang, F.; Hsu, Y.-H.; Chan, L.-C.; Xia, W.; Ke, B.; Zhu, C.; Deng, R.; Tang, J.; et al. CDK2-mediated site-specific phosphorylation of EZH2 drives and maintains triple-negative breast cancer. Nat. Commun. 2019, 10, 5114. [CrossRef] [PubMed]

68. Pellegrino, B.; Musolino, A.; Llop-Guevara, A.; Serra, V.; De Silva, P.; Hlavata, Z.; Sangiolo, D.; Willard-Gallo, K.; Solinas, C. Homologous Recombination Repair Deficiency and the Immune Response in Breast Cancer: A Literature Review. Transl. Oncol. 2020, 13, 410-422. [CrossRef]

69. Chen, C.-C.; Feng, W.; Lim, P.X.; Kass, E.M.; Jasin, M. Homology-Directed Repair and the Role of BRCA1, BRCA2, and Related Proteins in Genome Integrity and Cancer. Annu. Rev. Cancer Biol. 2018, 2, 313-336. [CrossRef] [PubMed]

70. Dietlein, F.; Thelen, L.; Reinhardt, H.C. Cancer-specific defects in DNA repair pathways as targets for personalized therapeutic approaches. Trends Genet. 2014, 30, 326-339. [CrossRef] [PubMed]

71. Christou, C.M.; Kyriacou, K. BRCA1 and Its Network of Interacting Partners. Biology 2013, 2, 40-63. [CrossRef] [PubMed]

72. Tanner, M.; Kapanen, A.I.; Junttila, T.; Raheem, O.; Grenman, S.; Elo, J.; Elenius, K.; Isola, J. Characterization of a novel cell line established from a patient with Herceptin-resistant breast cancer. Mol. Cancer Ther. 2004, 3, 1585-1592. [PubMed]

73. Friedland, J.C.; Smith, N.L.; Sang, J.; Acquaviva, J.; He, S.; Zhang, C.; Proia, D.A. Targeted inhibition of Hsp90 by ganetespib is effective across a broad spectrum of breast cancer subtypes. Investig. New Drugs 2013, 32, 14-24. [CrossRef] [PubMed]

74. Tanida, T.; Matsuda, K.I.; Yamada, S.; Hashimoto, T.; Kawata, M. Estrogen-related Receptor $\beta$ Reduces the Subnuclear Mobility of Estrogen Receptor $\alpha$ and Suppresses Estrogen-dependent Cellular Function. J. Biol. Chem. 2015, 290, 12332-12345. [CrossRef] [PubMed]

75. Yamane, M.; Nishiki, M.; Kataoka, T.; Kishi, N.; Amano, K.; Nakagawa, K.; Okumichi, T.; Naito, M.; Ito, A.; Ezaki, H. Establishment and characterization of new cell line (YMB-1) derived from human breast carcinoma. In Hiroshima J. Med. Sci.; 1984; 33, pp. 715-720. Available online: https://pubmed.ncbi.nlm.nih.gov/6534930/ (accessed on 13 April 2020). [PubMed]

76. O'Brien, N.; Conklin, D.; Beckmann, R.; Luo, T.; Chau, K.; Thomas, J.; Mc Nulty, A.; Marchal, C.; Kalous, O.; von Euw, E.; et al. Preclinical Activity of Abemaciclib Alone or in Combination with Antimitotic and Targeted Therapies in Breast Cancer. Mol. Cancer Ther. 2018, 17, 897-907. [CrossRef]

77. Jiang, G.; Zhang, S.; Yazdanparast, A.; Li, M.; Pawar, A.V.; Liu, Y.; Inavolu, S.M.; Cheng, L. Comprehensive Comparison of Molecular Portraits between Cell Lines and Tumors in Breast Cancer. BMC Genom. 2016, 17, 525. [CrossRef] [PubMed]

78. Gomez-Flores-Ramos, L.; Dean, M.; Jones, K.; Wang, M.; Villarreal-Garza, C.; Álvarez-Gómez, R.M.; Wegman-Ostrosky, T.; Reynoso-Noverón, N.; Fragoso-Ontiveros, V.; Sánchez-Zamorano, L.; et al. Clinically Relevant Germline Mutations in a Cohort of Young Women with Breast Cancer: A Comprehensive Analysis of Hereditary-Cancer Genes from Whole-Exome Sequencing. 2020. Available online: https://www.preprints.org/manuscript/202008.0718/v1 (accessed on 21 November 2021). 